\title{
Automatic Code Compliance with Multi-Dimensional Data Fitting in a BIM context
}

\author{
Patlakas $\mathrm{P}^{1}$, Livingstone $\mathrm{A}^{2}$, Hairstans $\mathrm{R}^{2}$, and Neighbour $\mathrm{G}^{1}$ \\ ${ }^{1}$ CEBE, Birmingham City University, Birmingham, UK \\ ${ }^{2}$ COCIS, Edinburgh Napier University, Edinburgh, UK
}

\begin{abstract}
BIM-based tools can contribute to addressing some of the challenges faced by structural engineering practitioners. A BIM-based framework for the development of components that deliver Automatic Code Compliance (ACC) is presented. The structural design problems that such components solve are categorised as simple, where ACC can be implemented directly, or complex, where more advanced approaches are needed. The mathematical process of Multi-Dimensional Data Fitting (MDDF) is introduced in order for the latter, enabling the compression of complex engineering calculations to a single equation that can be easily implemented into a BIM software engineering package. Proof-ofconcept examples are given for both cases: offsite-manufactured structural joists are utilised as a nonrecursive example, implementing the results obtained in the manufacturer's literature; the axial capacity of metal fasteners in axially loaded timber-to-timber connections are utilised as an example of recursive problems. The MDDF analysis and its implementation in a BIM package of those problems are presented. Finally, the concept is generalised for non-structural aspects at a framework level, and the challenges, implications, and prospects of ACC in a BIM context are discussed.
\end{abstract}




\section{Introduction}

There must be few terms in the realm of Architecture, Engineering, and Construction (AEC), in the past two decades at least, that have been as semantically fluid as Building Information Modelling (BIM). Perhaps the most-often quoted definition has been devised by the National Building Information Model Standard Project Committee, according to which BIM is "a digital representation of physical and functional characteristics of a facility" [1]. The core idea of BIM as an information resource, collectively used by AEC professionals, is fairly common [2] and goes back to the first years of research in AEC computing [3]. More recently, the advances in computing power and software development, and the adoption of software by all AEC disciplines has led many to view BIM as a process [4] or activity, occasionally differentiating between Building Information Model (the resource) and Building Information Modelling (the process or activity) [5].

The promise of BIM is both significant and wide-ranging. One of the standard textbooks on the topic [5] lists a number of benefits covering the entire lifecycle process, from Pre- to PostConstruction passing via Design and Construction \& Fabrication, while the beneficiaries include practically all stakeholders of the construction process. With such industry-transforming potential, it is not surprising that BIM has received significant attention across the sector. This ranges from standard activities such as architectural design $[6,7]$ and cost estimation $[8,9]$ to more specialised aspects such as energy consumption [10] and labour productivity [11].

Software vendors of the main structural engineering packages provide some level of BIM integration, mostly via Input/Output (I/O) tools with BIM-oriented architectural packages such as Autodesk Revit, and the generic Industry Foundation Classes (IFC) [12-14]. However, there are numerous issues with those: as early as 2008 , practising structural engineers were reporting considerable scepticism with vendors' promises of "seamless" links between packages [15]; the fact that interoperability is a major point of discussion in the review by Volk et al [16] suggests that it will remain a major concern in the foreseeable future. In addition, there is the recurrent issue of the complexity and steep learning curve inherent in BIM-oriented software, as well as the need to maintain parallel BIM infrastructures for different clients [15]. The Return of Investment (ROI) of BIM, especially for Micro, Small, and Medium Enterprises (SME) has long been a point of contention [17]; in structural engineering practice this can be even more demanding, as structural engineers already have to master complex structural analysis and design packages for completing the core tasks of their work. As such, any additional software package must demonstrate a considerable return to justify the overheads in time and resources.

The aim of this paper is to present an innovative approach for the automatic code compliance of design calculations in a BIM context. Structural timber design is utilised as an example, but there is significant potential for the approach to be generalised to other materials, and also to other aspects of building design altogether. The objectives of the presented work are:

- the development of a BIM-driven approach that allows the automatic code compliance of design calculations

- the application of a novel method which allows the streamlining of structural design calculations via Multi-Dimensional Data Fitting (MDDF)

- the integration of the outputs of said method in a BIM context, utilising "off-the-shelf" BIM scripting tools with minimum development overheads

- the presentation of a general conceptual BIM framework that allows the expansion of this work to all calculation-based aspects of design 
From an industry perspective, it is envisaged that the work presented here can support AEC practitioners who want to incorporate timber in their projects but are finding the level of technical expertise required a significant barrier.

\section{Methodology}

The development of such a BIM framework, which covers all the intended aspects, requires a sequenced approach and the utilization of techniques from various fields.

We begin with a survey of the current approach in structural timber design, in order to identify the role of the structural engineer within the timber design process, the interaction and data exchange with other disciplines, and the key design problems that a structural engineer is expected to solve. We continue by analysing the current approaches in existing BIM frameworks, in order to identify one which combines effectiveness with industrial applicability.

From the above, we are able to develop the framework at a conceptual level. This allows us to identify the key design problems the solutions to which we need to automate, in order to demonstrate the feasibility of the framework and its applicability and relevance in the timber design process.

We identify two general types of problems that a structural engineer has to solve:

- simple ("single-variable") problems, for which the majority of the structural calculations are either undertaken by the manufacturer or solutions can be easily found in the technical literature. An example would be identifying the spacings needed for floor joists, for a given span and a given cross-section.

- complex ("multi-variable") problems, for which a high level of technical knowledge and computational complexity is required. An example would be the design of a moment-resisting connection, where a range of options can be considered, such as the arrangement of the connection, the types and properties of fasteners, the fin or gusset plates etc.

The first category of such problems can be automated relatively simply and the integration in the framework in a straightforward process. We present such an implementation utilizing the standard scripting tools available in a BIM software package.

The second category of problems are significantly more demanding, and their complexity partially explains why the automatic code compliance found in structural timber design is limited. In order to address these obstacles, we draw on the mathematical technique of Multi-Dimensional Data Fitting. We present an environment we have developed within existing mathematical software, which enables complex problems to be solved; we present both the process and the capabilities of the software environment. We utilise this to solve a simplified version of a complex multi-variable problem, and we implement the outputs of the process in a BIM software package as before.

While the initial concept behind the framework, and the particular applications presented here, are focused on automating structural timber design problems, we consider that this can be generalised to address a number of similar problems and, theoretically, automate the building design process to a considerable extent. We present, in brief, a conceptual framework that is able to extend this process to numerous other problems. We close by acknowledging the limitations of the approach we followed, but also discuss its applicability and implications for building design.

\section{Automated Structural Timber Design in a BIM Context}




\subsection{The Structural Timber Design Process}

Construction projects are complex, heterogeneous, and distributed sociotechnical systems [18]; in a digital context, system integration is particularly important [19]. Structural design is one of the core areas of the building design process. The structural engineer has to interact not only with the architect but also via a range of other engineering specialities, either directly or via the architect, the project manager, or the contractor, depending on the nature and organisation of the project. A simplified schematic representation of the interactions (and thus data exchanges) between the architectural designer and some of the engineering disciplines for building design is given in Figure 1.

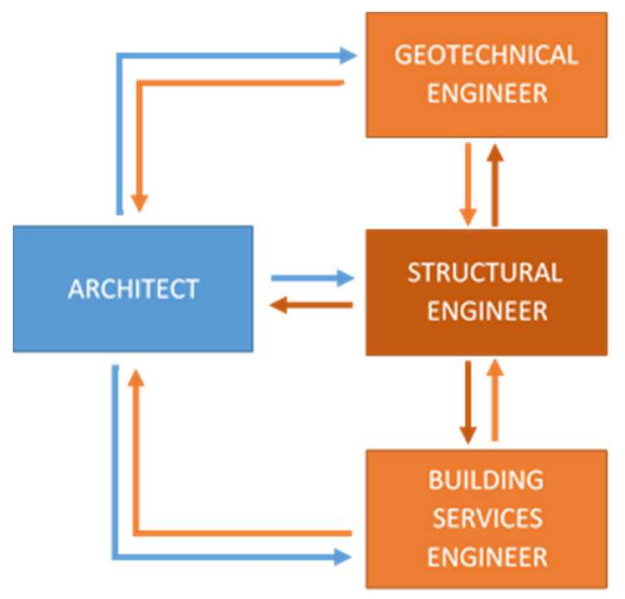

Fig. 1. Schematic representation of interactions between architect and some engineering disciplines in buildings

Even within the structural engineering domain, a range of processes take place. Those might be done in-house in different types of software or subcontracted to specialists. Thus more interactions and data exchanges take place. A simplified schematic representation of those for the case of timber structures is given in Figure 2, while more extended versions exist for case-specific problems [20].

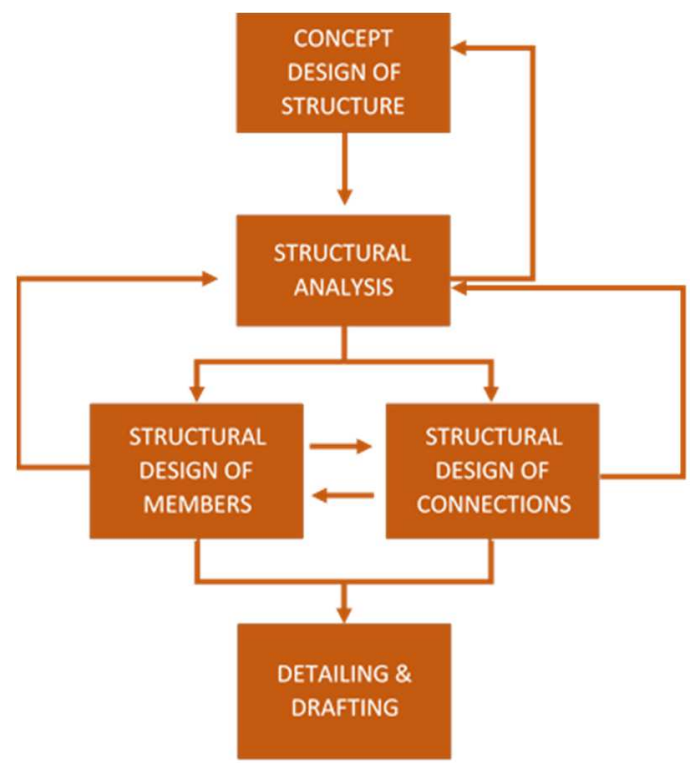

Fig. 2. Schematic representation of the different stages of the structural design of a typical timber structure

From the activities described in Figure 2, the structural design of members and, especially, connections poses particular technical challenges. It is telling that timber design is either omitted altogether from the mainstream structural engineering packages with BIM support [13, 21], or, when addressed, it is without the more technically challenging aspects, such as moment-resisting connections [22]. The latter, is usually the province of specialised software applications, often lacking 
effective BIM integration support [23]. The automatic code compliance of the structural design of such elements would offer significant benefits, addressing some of the challenges mentioned in the Introduction. The integration of this partial automation in a BIM context would also allow this to be combined with the well-established benefits of BIM [5] and thus contribute further to the take-up of timber by the wider AEC industry.

However, the computational and scientific complexity inherent in structural design, together with the aforementioned interoperability issues often present in BIM, mean that any automation needs to take place within a well-defined BIM framework, in order to fulfil its potential.

\subsection{Approaches in BIM frameworks}

As the definition of BIM is quite broad, it is useful to attempt to position the intended outcomes within the various levels of BIM possibilities. An often-employed scale is the BIM Levels or Stages. As defined by Succar [24] Stage 1 represents object-based modelling, Stage 2 represents collaborative working, utilising at least one collaborative model, while Stage 3 aspires to interdisciplinary $\mathrm{nD}$ models with network-based integration and synchronous exchange of model and document data. Understandably, the author recognises that Stage 3 would require fundamental changes in the modus operandi of the entire AEC industry, as well as significant maturity in network $\&$ software technologies. Though Succar was writing in 2009, a description of the same concept (referred to as "Level 3") in the National Building Specification website, originally written in 2014 but not updated at the time of writing of this paper, refers to it as the "holy grail" [25].

Existing approaches can be said to belong to one of two categories, defined here as "single platform BIM" (SP-BIM) and "multi-platform BIM" (MP-BIM). Single platform BIM relies on the utilisation of either a single piece of BIM software or a small range of BIM-compatible software applications, typically from the same vendor or as part of the same suite. This ensures I/O consistency and thus minimizes the development overheads. Other software packages might be used for non-BIM operations and, overall, SP-BIM is closer to Stage/Level 2. By contrast, multi-platform BIM allows the use of a wide range of BIM-enabled software packages, targeted at different disciplines and developed by different vendors. Data I/O might be done via the IFC or via middleware developed within the context of professional project or research project. Conceptually, this is closer to Stage/Level 3. A brief summary of the two definitions is given in Table 2.

Table 2. Single/multi-platform BIM description

\begin{tabular}{|c|c|c|}
\hline Term & BMV functionality & $\begin{array}{l}\text { BIMI } \\
\text { Level }\end{array}$ \\
\hline $\begin{array}{l}\text { Single-platform BIM } \\
\text { (SP-BIM) }\end{array}$ & $\begin{array}{l}\text { Concentrated in a single application, or a small number of } \\
\text { applications with verified interoperability (typically from } \\
\text { a single vendor) } \\
\text { External hardware, datasets, and calculations processes } \\
\text { are handled via customized I/O tools. }\end{array}$ & 2 \\
\hline $\begin{array}{l}\text { Multi-platform BIM } \\
\text { (MP-BIM) }\end{array}$ & $\begin{array}{l}\text { Allows the use of multiple BIM software packages, from } \\
\text { many, or any vendor. } \\
\text { This includes all, or most, hardware, datasets, and } \\
\text { calculation processes. }\end{array}$ & 3 \\
\hline
\end{tabular}

The relatively straightforward implementation of this approach means that it has been utilised for a wide range of AEC tasks and problems. Wang et al developed a framework for enabling facilities managers to engage in the design of a building [26] via SP-BIM, while McArthur suggested 
a framework for the operations phase, where the main interaction is between a facilities management and a BIM system [27]. Song et al developed a structural BIM framework for construction planning and scheduling and implemented it via Open Cascade, a generic 3D modelling C++ kernel [28], using IFC and Microsoft Excel files as data I/O mechanisms. Porwal and Hewange proposed a BIM-based framework for public-private partnering in public construction projects [29] utilising the Autodesk suite of products to ensure compatibility.

Similar approaches are also applicable to more specialised requirements. Choi et al [30] as well as Chavada et al [31] have applied it to the problem of work-space planning and management; in both cases, a single BIM environment was utilised to enable $\mathrm{nD}$ modelling and resolve conflicts. Addressing more technical issues, Kim et al developed a framework that enables the dimensional and surface quality assessment of precast concrete elements [32]; as a key part of the work involved primary data collection via laser scanning, the focus of the framework was not BIM per se, but I/O interoperability with a BIM system. Thus, IFC was used as the data format, and a single BIM platform was utilised for achieving the objective. Park et al produced a framework to link augmented reality with a BIM to facilitate defect identification and management [33]; in this, the provided mockups suggest that the envisaged implementation would be via an SP-BIM.

An earlier review by Cervosek [34] found that effective integration largely worked only within "tightly coupled" solutions, i.e. when the software developed has invested significantly in data $\mathrm{I} / \mathrm{O}$; typically this is the case only within applications from a single vendor, while users that attempt data I/O between applications from different vendors are faced with loss of information which often results in significant time loss for manual data input and remodelling.

Researchers working on multi-disciplinary problems have typically had to engage more with a MP-BIM approach. Singh et al developed a theoretical framework which, crucially, addresses server issues and thus computing/software requirements of a more technical nature [35]. Working with a range of different software packages and platforms, they identified an extensive set of technical requirements, ranging from model organisation and data security issues, to the various aspects of administrative, training, and legal support required. It is interesting that these challenges are raised for a case that concerns only architectural design, hydraulics, and lighting, while the emphasis is on the visualisation and not detailed calculations. As such, even this extensive and highly detailed framework is unlikely to be able to satisfy the considerable computational demands of the structural engineering aspects of design.

Similar limitations can be identified in other work: Ding et al developed a framework intended to provide computable $\mathrm{nD}$ [4]. The work is comprehensive and provides important pointers to areas for further BIM research; however, the computation described is highly unlikely to satisfy the requirements of the state-of-the-art of structural design. Similarly, frameworks suggested by Lu and Olofsson [36] and Kadolsky et al [37] deal with the immediate problem of compatibility between heterogeneous data and integration of different knowledge domains but provide limited scope for advanced computational applications.

The direct integration of computationally demanding approaches such as Finite Element Analysis (FEA) in an MP-BIM environment appears unlikely to be achievable in the foreseeable future [38]. It is characteristic that Volk et al [16] identified only one structural analysis-related innovative BIM process in their review. In this, Lee et al [39] rely on heuristics in order to satisfy the structural safety requirements they set, even when effectively using an approach closer to SP-BIM.

\section{A BIM Framework for the Automatic Code Compliance of Structural Timber Design}




\subsection{Development of a BIM framework}

The analysis of existing research frameworks demonstrates that the effective automaton of structural analysis and design computations in BIM cannot be achieved via an MP-BIM approach, at least with the current state-of-the-art in hardware and software. It introduces an extensive set of technical challenges, without any tangible benefit. As described in the Introduction, the current practice of structural analysis and design software is to treat BIM as a data $\mathrm{I} / \mathrm{O}$ issue as opposed to core functionality. Thus it appears reasonable to adopt an SP-BIM approach addressing the structural computational aspects indirectly, as separate knowledge domains.

The framework developed for the purposes of this work assigns an SP-BIM system as the core interdisciplinary modelling and management domain; individual components are analysed and designed from a structural engineering perspective so as to achieve Automatic Code Compliance (ACC), meaning they satisfy the structural design requirements according to the respective national code/standard. The results of the ACC analysis are programmed into BIM components; these BIM components are input in the core BIM platform and are available to designers. A schematic representation of the process for the development of the framework is given in Figure 3.

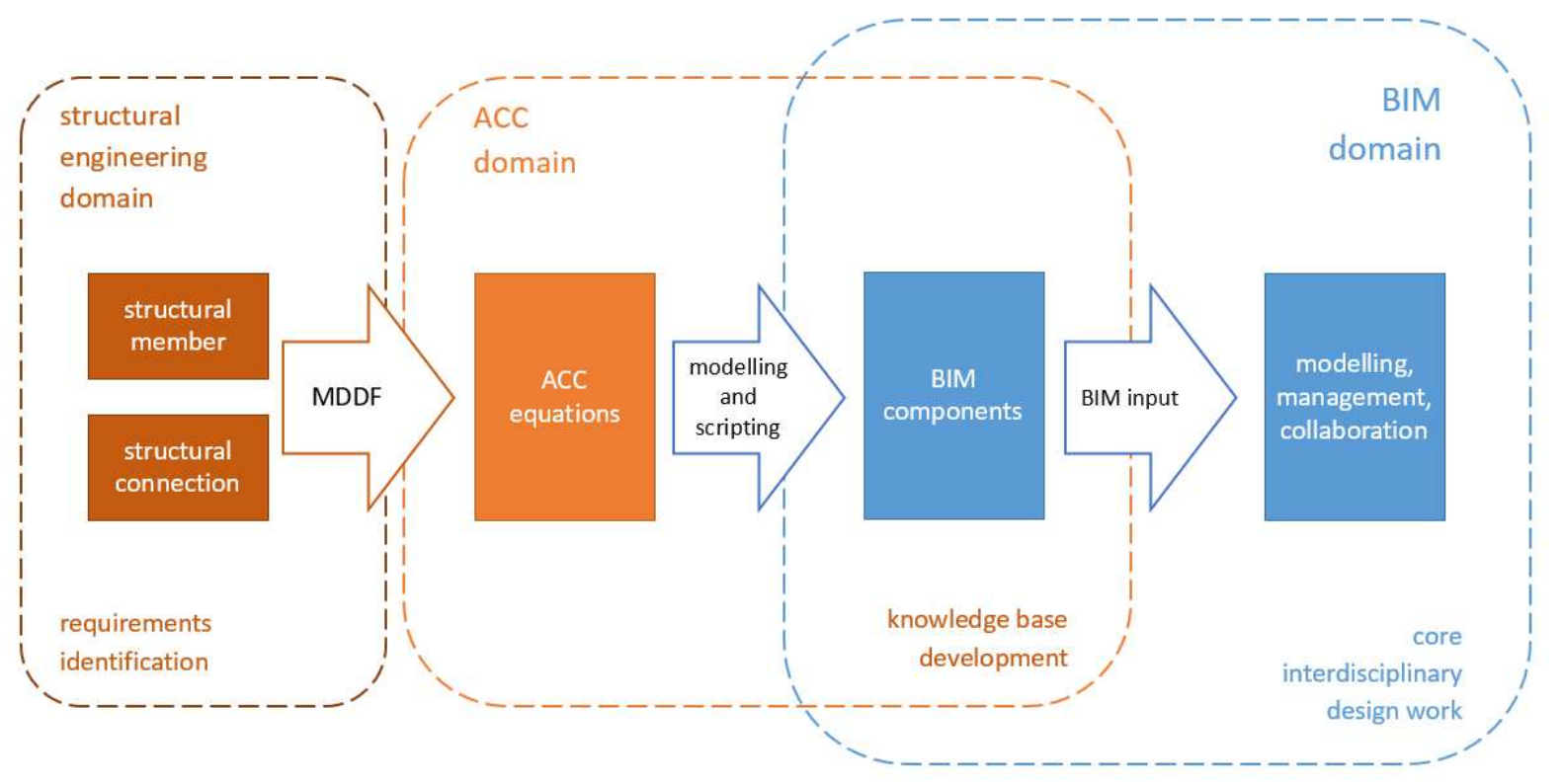

Fig. 3. Schematic representation of the framework development process

When design decisions are made that affect the structural performance, and thus the code compliance of BIM components, the latter respond in real-time to the design decisions. Typically, the components respond to design decisions in one of the following ways:

i. by adjusting themselves automatically, so as to achieve code compliance. For example, a beam might change cross-section, or the joist spacings of a floor might change. This enables ACC, while maintaining the design intention (e.g. dimensions of a floor).

ii. by providing limiting values, so the designer is protected from going beyond the code. For example, if a beam cannot support the type of loading beyond a certain span, the respective BIM component will be limited to be designed up to a certain span.

iii. by providing immediate feedback on the structural performance of a component, in nonexpert terms, thus allowing the designer to identify if the component is fit for purpose. For example, a connection can identify that, with the given materials and geometry, it can withstand typical loads for residential buildings, but not for commercial. 
As a result of this process, and assuming only ACC BIM components have been used, the entire design is code-compliant, without having to resort to costly and inaccurate $\mathrm{I} / \mathrm{O}$ from structural engineering software. The SP-BIM approach allows the designer to focus the BIM aspects of the work where the technology performs best, namely 3D modelling, information management, and interdisciplinary collaboration without engaging with the complexities of MP-BIM, which is arguably not mature enough for effective use in contemporary professional practice, at least in its full envisaged Level 3 breadth.

For the purposes of this work, Autodesk Revit $\odot$ was utilised as the SP-BIM technology. The selection was taken partly due to the popularity of the software in the UK and partly due to the satisfactory scripting capabilities which allow the integration of the ACC results without undue complexity. The general framework, however, could be applied within any BIM platform.

Naturally, the success of the framework described in the previous subsection rests on the development of a suitable ACC knowledge base, the outputs of which are utilised to program the respective BIM components. It is important, therefore, to identify the types of ACC problems that can arise, so appropriate examples can be developed in order to demonstrate the feasibility of the approach.

\subsection{Automatic Code Compliance for Structural Engineering}

Automated Code Compliance is not a new topic within the BIM community. The origins can be tracked down to the work of Steven Fenves, who in the 1960s was publishing work on decision table formulation [40, 41], thereby creating a foundation for ACC. However, the main applications of ACC so far have focused on issues such as the design of the building envelope from an environmental perspective [42, 43]. Compliance has been achieved via different approaches, such as rule or textbased interpretation. Different logical approaches have been utilised such as: simple logical approach [44-46]; predicate [47, 48]; deontology [49]; ontological [50, 51]; object-based [44, 52-59]; programmatic [60]; machine learning [61]. It appears that the current literature on ACC relating to structural design within BIM focuses mostly on the design concept as opposed to industry application [38, 59, 62-72]. Ismail draw from a core volume on Object-Oriented Methods [73], in order to argue that, while different techniques and methods will continue to develop, the challenge if the selection and integration of those, presumably in a coherent and user-friendly whole [74]. The implementation of 'Smart' BIM objects as used in this research draws upon examples of 'intelligent' objects as presented by Sacks $[75,76]$, while the term 'semantic enrichment' has been employed by researchers as a 'catchall' term for the integration of 'smart' information into a BIM model [77, 78].

Some structural aspects of ACC are directly implementable in BIM platforms. A typical example is look-up tables. Before the advent of computers, everyday structural engineering practice relied heavily on such tables for identification of aspects such as appropriate cross-section sizes etc. While the proliferation of software has diminished their importance, they're still popular in professional reference guides [79] and manufacturers' literature [80]. Typically, these reduce to single-variable problems: for example, for a given type of timber joist and given structural loading and support conditions; the engineer can find the necessary joist spacings in a lookup table. The implementation of such single-variable ACC aspects in BIM is both feasible and with significant benefits, however, currently it appears underutilized by timber manufacturers who instead prefer to offer either detailed analysis software [81] or in-house design services [82].

Many other aspects, however, are much more complex and computationally intensive. Contemporary structural codes and standards are developed under the assumption that they will be interpreted and applied by highly qualified and experienced practitioners. They incorporate simplified or generalised versions of the scientific state-of-the-art, which rests on models developed and refined over decades (structural design) or centuries (structural analysis). Software developed to support engineers that work with these codes relies on complex algorithms. From a computer science 
perspective, ACC is often unfeasible with existing approaches as, for multi-variable optimisation problems, recursion issues appear, i.e. calculation functions would need to refer to themselves. Thus, the current state-of-the-art relies on the interoperability between a BIM platform and various structural analysis and design software applications, with the issues of performance and data $\mathrm{I} / \mathrm{O}$ described in the Introduction.

It appears then that both types of problems must be solved in order to demonstrate the feasibility of the framework. The first involves the solution of single-variable problems, utilising precalculated examples. The second involves the solution of complex, multi-variable problems, where more advanced techniques need to be used.

For the purposes of this work, we have identified two examples that correspond to these two categories. The examples had to be common, so as to reflect typical design problems, and representative of the process, so the approach could generalizable to all problems of this type. In addition, as described in Section 3.1, structural timber design involves the design of members and the design of connections, so it was important to cover both aspects.

As a simple problem, we chose the design of a structural member, a proprietary engineered joist. This is described in Section 5.

As a complex problem, we chose the design of a structural connection, with metal dowel-type fasteners. Connection design is one of the most challenging aspects of timber design in general, and Eurocode 5 in particular. The combination of timber's anisotropicity and the complexity of the scientific state-of-the-art mean that even basic connections demand highly detailed calculations. In the UK context, the difference in design philosophy between Eurocode 5 [83] and the previous British Standard [84], with Limit State Design as opposed to Permissible Stress Design, poses an additional barrier for practitioners [85].

This is covered in detail in Section 6.

\section{Member Design}

The structural design of timber members for typical applications is generally straightforward and, as described in Section 3, a range of timber component manufacturers provide relevant literature. A proprietary engineered joist system was selected, intended for use in flat roofs and domestic floors. The manufacturer produces an extensive technical manual, which includes not only structural design information but also, environmental, fire, durability, and detailing information [86]. The structural requirements cover both Eurocode 5 [83] and the previous British Standard, BS 5268-2 [84]. In design practice, the consulting structural engineer has to identify the design case and then manually specify the appropriate joist size and select the appropriate joist spacings based on the manufacturer's guidance. The intention here was to automate the spacing selection, for a given structural design size.

The implementation relied on developing a range of "Smart" BIM objects, in the form of Revit Families [87]. Revit's inbuilt scripting functions were used in order to apply the design instructions given in the manufacturer's technical manual (Figure 4). 


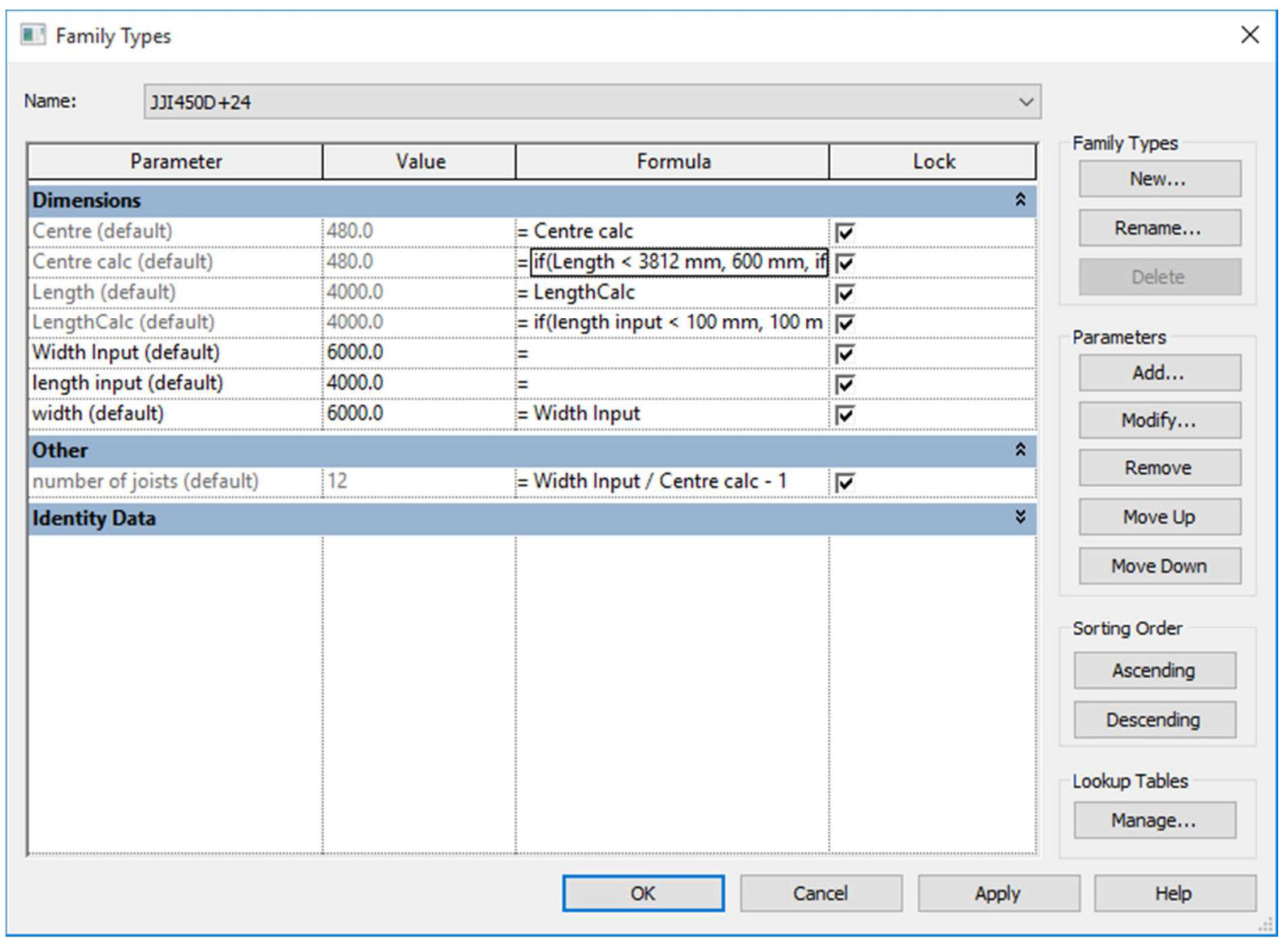

Fig. 4. Sample "Smart" joist scripting environment.

Once developed, these objects can be loaded into any existing Revit project. The core intelligent/ACC criterion is the joist spacing. Specifically, the user can select a type of joist based on the allowable depth s/he wants to include. When the joists are locked to supporting walls, the respective required spacing is automatically calculated, drawing from the maximum permissible loading values the manufacturer provides. The ACC behaviour continues throughout any modifications to the project. If, for example, the designer changes the span of a floor, the joist spacings are automatically recalculated and the $3 \mathrm{~d}$ model automatically adjusted, so as to conform to the structural design code (Figure 5).

Moreover, span minima and maxima included in the manufacturer literature are included in the model in the form of constraints. If the user goes outside this allowable domain, the software flags the constraints accordingly.
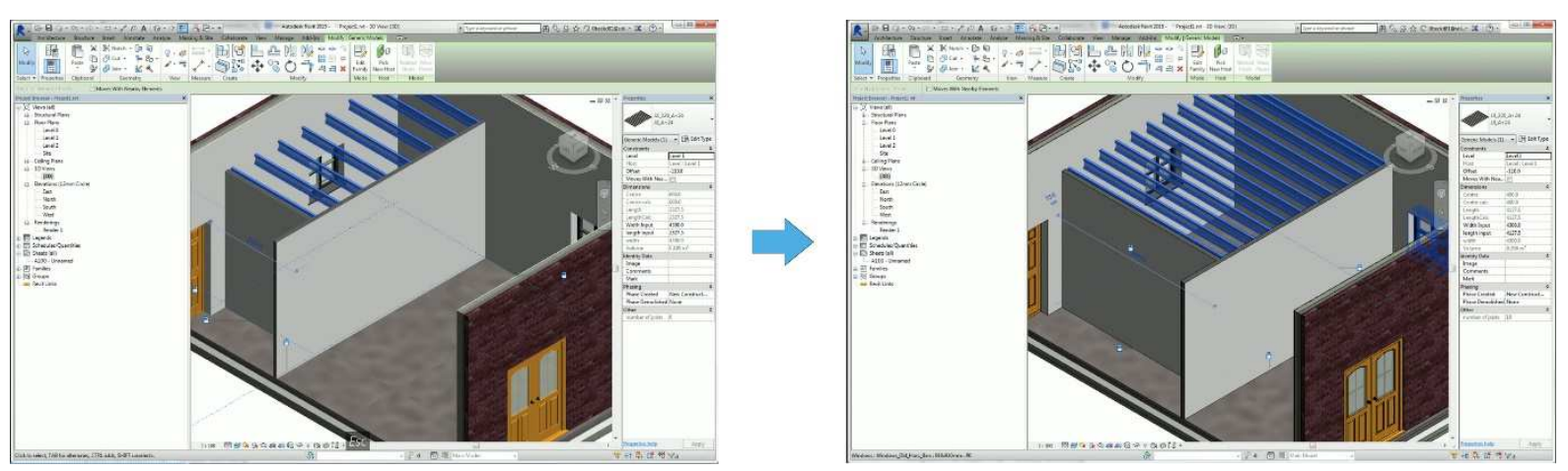

Fig. 5. Automatic recalculation of spacings and remodelling of floor joists triggered by span change. 
The main scripting aspects were developed by one of the authors. As part of an undergraduate student project under the supervision of one of the authors, Beck [87] developed a total of 33 domestic floor joist objects and 33 flat roof joist objects, implementing the entire joist catalogue of the manufacturer. The motivation was to evaluate the suitability of the scripting approach for the development of large databases of 'smart' BIM objects. The objects were made available for education (non-commercial) purposes via a purpose-built website, which also included a training video for the use of the software [88]. Further implementation details can be found in Beck [89]. While the output was highly praised by industry representatives in a dissemination event, the website itself saw little professional usage. It is likely that this was due to the restriction of having only one type of 'smart' object (joists) from only one manufacturer, suggesting that in order for the approach to be commercially viable, much more diverse object libraries would need to be created.

\section{Connection Design}

\subsection{Axial Loading of Fasteners}

A typical timber-to-timber connection with metal dowel-type fasteners subjected to axial loading was selected (Figure 6). While not a particularly complex problem, it is very common in practice, and reflective of the design process of more elaborate connections. The standard adopted for the structural design was Eurocode 5 (EC5) [83], generally considered the state-of-the-art structural timber design code internationally. All references to clauses and equations below refer to this standard.

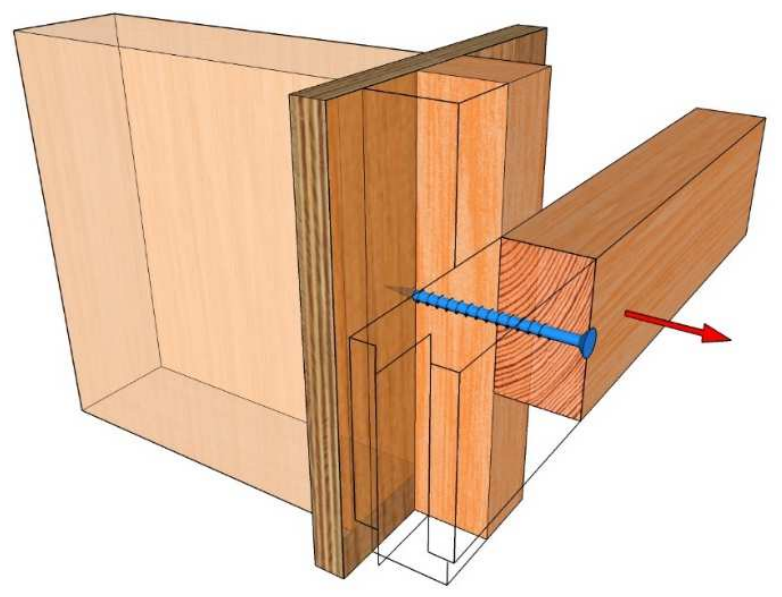

Fig. 6. Timber-to-timber connection with fastener under axial loading

According to Eurocode 5 (Clause 8.7.2(1)) there are six possible failure modes for axially loaded screws, not all of which will be relevant in this case. Specifically:

- the tear-off failure of the threaded part of the screw applies only when steel plates are used, and is thus not relevant

- the screw is in tension, and thus buckling failure is not relevant

- failure along a group of screws, together with steel plates is not relevant

The key consideration in the design of such connections is the withdrawal failure, namely: 
- Withdrawal failure of the threaded part of the screw (point side), referred below with the symbol $F_{\text {ax,point,Rk }}$

- Pull-through failure of the screw head (head side), referred below with the symbol $F_{\text {head,Rk }}$

These are calculated from Equations 8.40a and 8.40b of Eurocode 5 respectively [83].

The tensile failure of the screw, calculated according to Equation 8.40c. following on EN14592 [90] and tests described in EN1383:1999 [91], is theoretically applicable. However, for the screws used in the experiment, the characteristic tensile strengths given by the manufacturer are between $2.8 \mathrm{kN}$ and $11.5 \mathrm{kN}$. These would be greater than the withdrawal capacity by an order of magnitude between 5 and 10. As such, and in line with common engineering practice, they were not taken into account in the generation of the datasets. It should be noted that this was done for optimisation purposes only, and this failure mode could have been easily added for a different design case where it was relevant.

The total characteristic withdrawal capacity for screws, referred to as $F_{a x . R k}$, can therefore be calculated from

$$
F_{\text {ax.Rk }}=\min \left(F_{\text {ax.point } . R k}, F_{\text {head.Rk }}\right)
$$

This capacity is affected by eight different variables: the thread point side penetration $t_{\text {pen }}$; the screw head and outer thread diameters, $d_{h}$ and $d_{0}$ respectively; the pointside withdrawal strength $f_{a x . k}$ and the headside pull-through strength $\mathrm{f}_{\mathrm{h} . \mathrm{k}}$; the characteristic density of the timber member $\rho_{\mathrm{k}, \mathrm{m}}$; the associated densities for the two strengths, $\rho_{\mathrm{hss}}$ and $\rho_{\mathrm{pss}}$ respectively.

While look-up tables can be developed for specific types of components, this is not possible for a generalised case that covers all possible combinations of materials and screws. In order to develop the required BIM-implementable ACC database then, a different approach was needed. For this purpose, we utilised MDDF.

\subsection{Multi-Dimensional Data Fitting for Multi-Variable ACC}

Multi-Dimensional Data Fitting (MDDF) refers to the mathematical process that allows the fitting of datasets with an arbitrary number $n$ of dimensions. Data fitting in one or two dimensions are commonly used in a range of fields. The simplest form of data fitting (with $n=1$ ) is the common onedimensional (1-D) curve fitting, where a mathematical equation is derived from a series of data points. For $n=2$ it is typically referred to as surface fitting; in this, a mathematical surface is generated so as to pass through or close a 2-D dataset. MDDF is the generalisation of this process to $n$-D, allowing the derivation of multi-variable algebraic expressions from extremely large datasets. As a mathematical method, it is neither new nor obscure: it is widely used in a variety of scientific fields to study topics such as gene expression [92] and population synthesis [93]. Significant efforts have been made the past three decades to improve and enhance the various aspects of the technique from a mathematical and computing perspective [94-96].

Despite its considerable potential and wide applicability, however, it has not been widely used within the structural engineering field. One obstacle is the high cost of structural engineering experiments, which practically mean that the datasets are very small. A secondary potential reason is that MDDF outputs, while highly useful to predict behaviour, might not necessarily provide as useful insights into the physical behaviour of a system compared to analytical models.

However, MDDF can be particularly useful for the purposes of ACC. It allows the substitution of a complex, multi-equation structural calculation algorithm with a single equation. This single equation might be extensive but it is significantly lighter in implementation from a 
computational perspective. More importantly, it allows multi-variable problems to be solved simultaneously, and thus enables ACC features to be integrated into a "Smart" BIM component.

The programming of these "Smart" BIM components draws from an appropriate knowledge base. The development of such a knowledge base presents two challenges: firstly, identifying or developing suitable datasets that allow the application of MDDF techniques to derive the singleequation output; secondly, the application of the MDDF technique itself, which can be mathematically demanding. The following sections describe how these challenges were addressed in this project.

\subsection{The MDDF Environment}

While there are a number of software platforms available for fitting nonlinear multidimensional data, the particularities of this project meant that none provided the required functionality. As such, a customised MDDF platform was developed, based on the MATLAB computing environment, utilising the inbuilt nonlinear least-squares solver 'Isqcurvefit' [97]. This function is effectively a least squares estimator, based on the Levenberg-Marquardt algorithm (LM), and trust-region-reflective algorithm methods [98-100]. The first iteration of an LM algorithm can be traced back to 1944 [101], with subsequent improvements in the 1960s [102] and 1970s [103], with further refinement of the goodness-of-fit published in 1980 [104]. The MDDF platform developed for the purposes of this work extends the 'Isqcurvefit' functionality to multiple dimensions. In addition, it includes a Graphical User Interface (GUI) allowing visual inspection of data with full user ability to interrogate any of the $n$ number of dimensions.

An overview of the fitting procedure for different numbers of dimensions is presented in Figure 7, where $\tau$ is the number of data points to be fitted; $i$ is the number of iterations, or points, along each dimension; $d$ is the number of dimensions. 


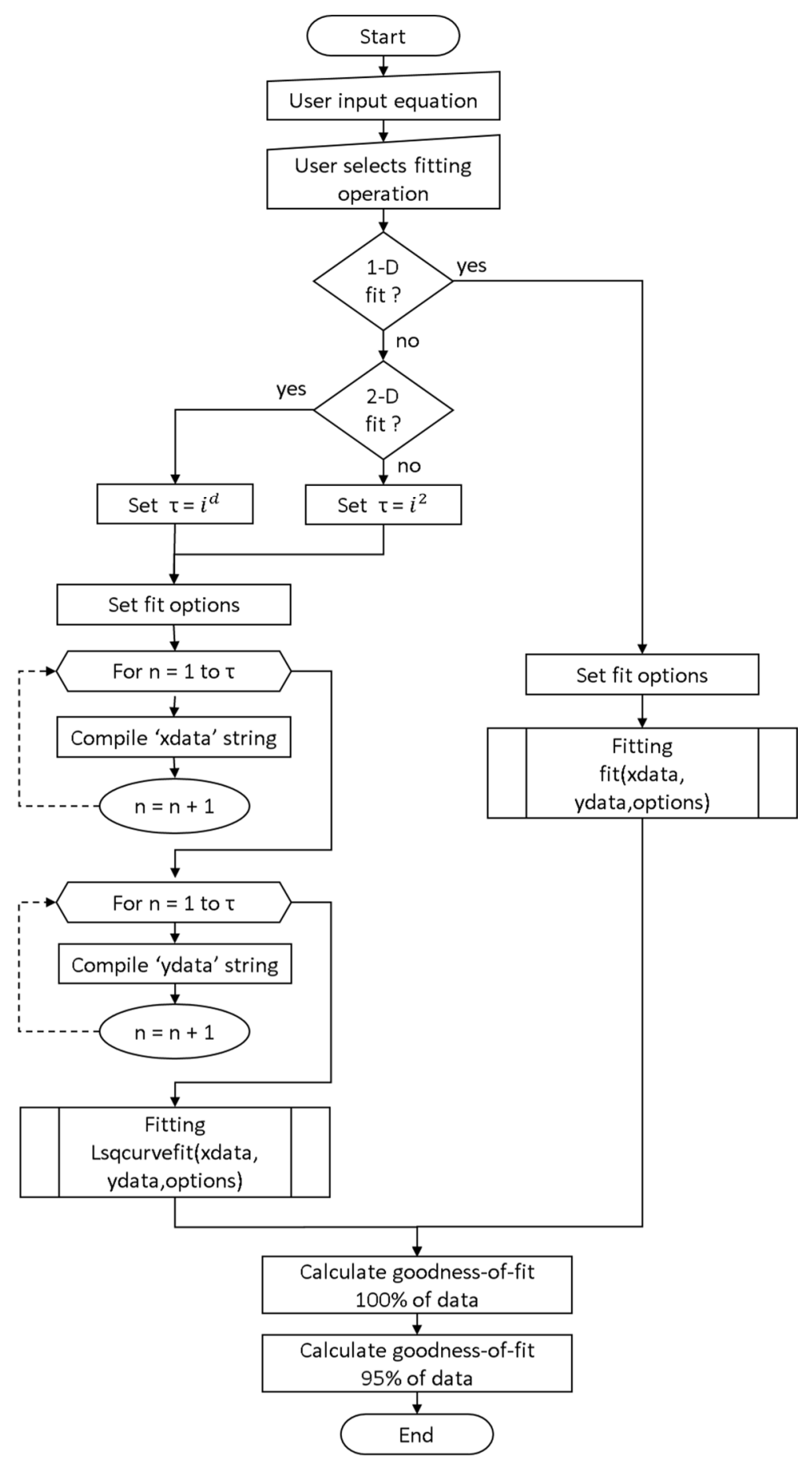

Fig. 7. Overview of the fitting procedure within the new fitting software

The platform interface presents the user with a number of options for fitting the data. One, two, or all dimensions can be fit at once (Figure 8), while a numerical indicator of goodness-of-fit (for $100 \%$ and $95 \%$ of the data) is provided. The GUI allows visual inspection of the data against the fit, thus providing the user with a greater level of confidence (Figures 8 and 9). 


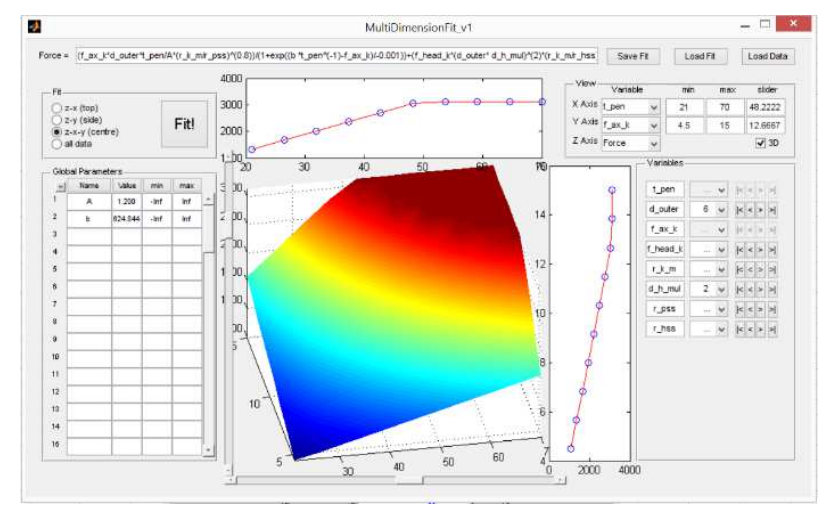

Fig. 8. GUI Screenshot

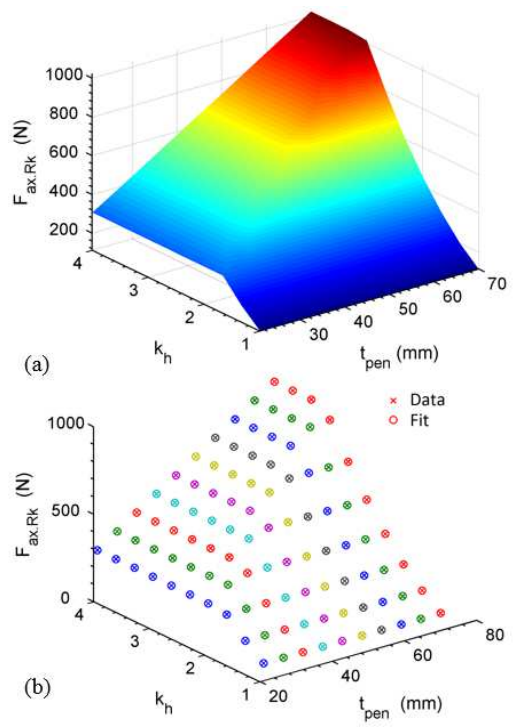

Fig. 9. Data and fit comparison

\subsection{Application of MDDF in the example}

The application of MDDF in this connection example requires the creation of large datasets, developed within MATLAB utilising nested loops of the automated design code calculations. These are then used for the extraction of fitted equations, using the MATLAB-based environment described above, and the outputs can then be introduced in a BIM object. The process is summarised in Figure 10.

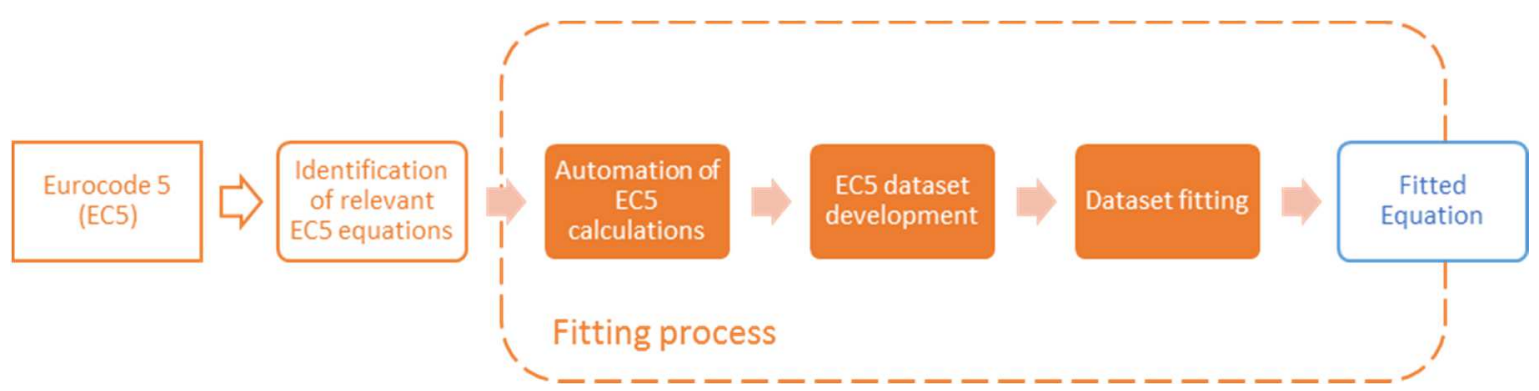

Fig. 10. Fitting Process Overview 
The dataset developed for the axial loading example was based on eight variables with ten iterations each, thus resulting in $10^{8}$ data points, which provides a large enough dataset for the fitting process. The variables and their boundary conditions are given in Table 3 .

Table 3. Boundary conditions of the axial withdrawal loading dataset

\begin{tabular}{lc|cc} 
& & Minimum & Maximum \\
\hline Thread point side penetration & $t_{\text {pen }}$ & $21 \mathrm{~mm}$ & $70 \mathrm{~mm}$ \\
Screw outer thread diameter & $d_{o}$ & $3.5 \mathrm{~mm}$ & $6 \mathrm{~mm}$ \\
Head factor (ratio) & $k_{h}$ & 1 & 4 \\
$\mathrm{k}_{\mathrm{h}}=\mathrm{d}_{\mathrm{h}} / \mathrm{d}_{0}$ & & & \\
Pointside withdrawal strength & $f_{\text {ax.k }}$ & $4.5 \mathrm{~N} / \mathrm{mm}^{2}$ & $15 \mathrm{~N} / \mathrm{mm}^{2}$ \\
Head side pull-through & $f_{h . k}$ & $4.5 \mathrm{~N} / \mathrm{mm}^{2}$ & $15 \mathrm{~N} / \mathrm{mm}^{2}$ \\
Member timber density & $\rho_{k_{-} m}$ & $290 \mathrm{~kg} / \mathrm{m}^{3}$ & $460 \mathrm{~kg} / \mathrm{m}^{3}$ \\
Associated density for $f_{h_{-} k}$ & $\rho_{\text {hss }}$ & $290 \mathrm{~kg} / \mathrm{m}^{3}$ & $460 \mathrm{~kg} / \mathrm{m}^{3}$ \\
Associated density for $f_{\text {ax_k }}$ & $\rho_{\text {pss }}$ & $290 \mathrm{~kg} / \mathrm{m}^{3}$ & $460 \mathrm{~kg} / \mathrm{m}^{3}$
\end{tabular}

As equation 1 demonstrates, the dataset is made up of two separate intersecting surfaces, therefore by using the intersection of the two surfaces the dataset can be quantified using an equation. For this purpose, a sigmoid function is used as a form of a step function. The basic form of a sigmoid function can be seen in equation 2 and Figure 11.

$$
y=\frac{1}{1+e^{-\left(\frac{x+\varepsilon}{\omega}\right)}}
$$

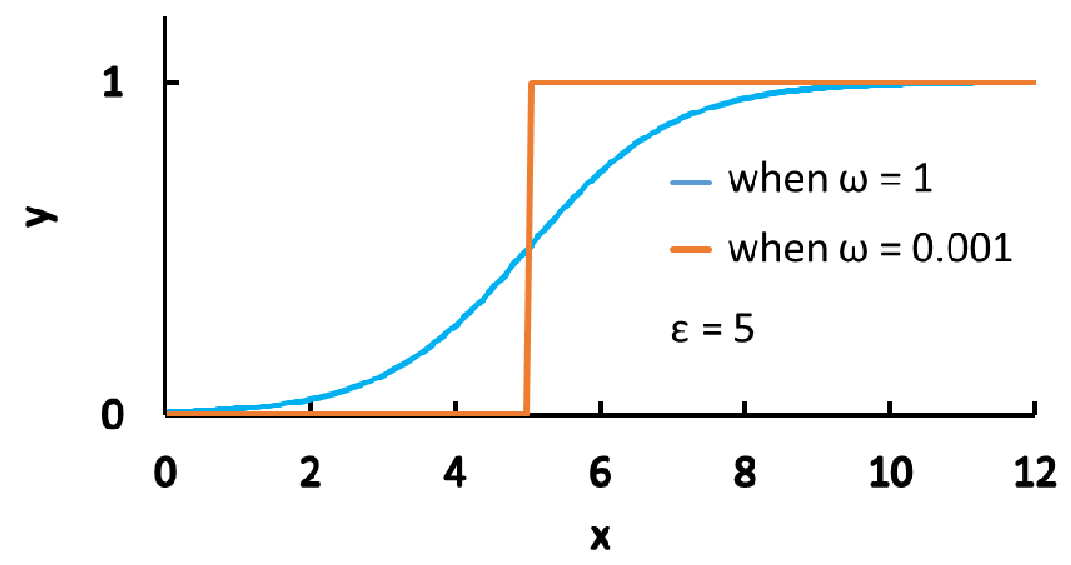

Fig. 11. Sigmoid function example

The generic surface intersection fitting follows the process described in Figure 12. 


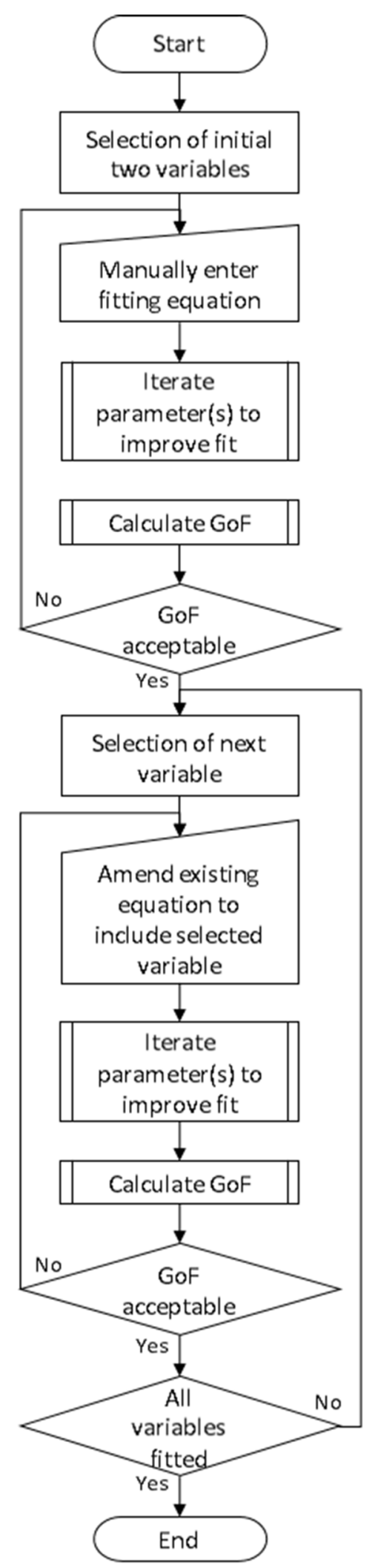

Fig. 12. Surface fitting process

The application of the methodology in this axial loading example is described below.

Step 1: The process requires the selection of two suitable variables where a clear intersection of the two surfaces can be observed while keeping the rest fixed. Here, the penetration length $t_{\text {pen }}$ and the pointside withdrawal strength $f_{a x, k}$ have been selected. The user is required to enter an initial equation 
that describes the relationship of the surface intersection into the fitting software, with the appropriate fitting parameters and starting points (Figure 13a). The software runs iterations until the best fit of the parameter is found, coinciding with the intersection of the surface planes. If the fitted equation does not have the required level of fit or Goodness of Fit $(\mathrm{GoF})$, either a more appropriate initial value for the fitting parameter is required, or the initial equation needs to be amended.

Step 2: The next variable selected is the headside pullthrough strength $\mathrm{f}_{\mathrm{h}, \mathrm{k}}$. This dataset, including both $t_{p e n}$ and $f_{a x, k}$ results in surfaces with a different relationship to Step 1 (Figure 13b). The observation of the shape of the dataset can be useful to provide a starting point for the variable that will be input into the fitting equation. The software then attempts to fit the equation, as per Step 1.

Steps 3 to 5 repeat the same process as Step 2, progressively including all variables, until finally, the resulting fitted equation includes the complete dataset. The shapes of the datasets on each step can be seen in Figure $13 \mathrm{c}$ to $13 \mathrm{e}$.

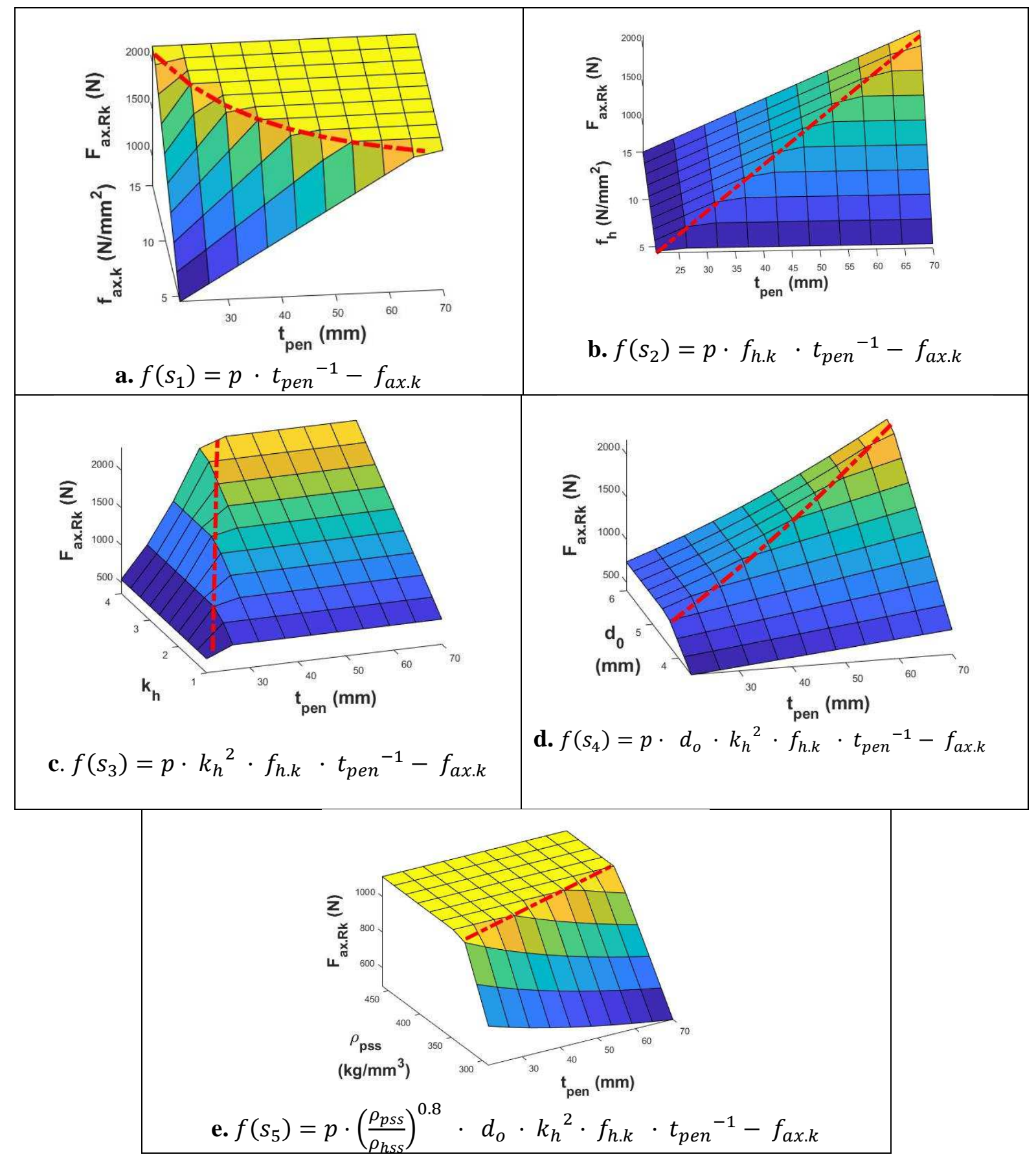


Fig. 13. Surface fitting process steps for the axial loading example

Equation 3 describes the final fitted surface intersection, where the algebraic validation is the point of intersection when $F_{\text {ax.point.Rk }}=F_{\text {head.Rk }}$, and the resulting multiplication factors have been rounded up towards safety.

$$
f(n)=1.2 \cdot\left(\frac{\rho_{p s s}}{\rho_{h s s}}\right)^{0.8} \cdot d_{o} \cdot k_{h}{ }^{2} \cdot f_{h . k} \cdot t_{p e n}{ }^{-1}-f_{a x . k}
$$

Combining the fitted intersection equation with the sigmoid form, a final equation can be derived, which accurately describes the complete 8D dataset (Equation 4).

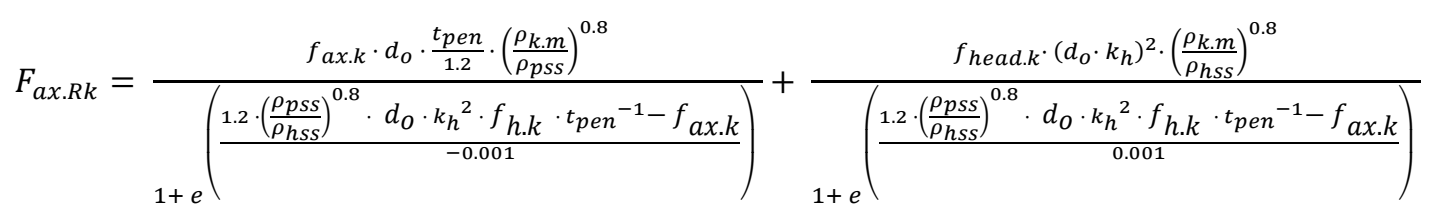

The final fitted equation was validated algebraically and verified experimentally, according to standard structural engineering practice; further details of the validation and verification process can be found in Livingstone et al [105].

For this axially loaded example the resulting computational loading for the fitted equation is $32.0 \%$ of the original. These computational benefits increase exponentially as the calculation complexity increases. For example, work currently in development has demonstrated a computational load of $9 \%$ for a laterally loaded connection, under a six-mechanism failure model.

\subsection{Integration into a BIM environment}

It was decided that, in order to maximize efficiency, the developed "Smart" BIM object would be an entire timber frame wall, hosting the axially loaded detail. This was implemented in Revit as a Generic Family component (Figure 14).

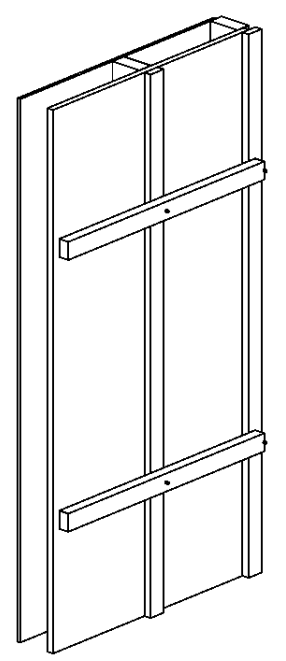

Fig. 14. The base Generic Family component of the Timber Wall

A number of custom parameters were set up in order to provide the designer with a suitable range of options, which would satisfy the requirements of a typical project. These can be separated in two categories: macro-level parameters, relating to geometry and physical properties of the entire wall 
system, and micro-level parameters, relating to geometric and physical properties of the fastener under axial loading. The parameters and their respective categorization in the proof-of-concept implementation are given in Table 5.

Table 5. Categorisation of Instance parameters

\begin{tabular}{|c|c|c|}
\hline Parameter & Allowed values & Description \\
\hline \multicolumn{3}{|c|}{ Macroscopic parameters } \\
\hline Stud centres 1 & $\begin{array}{l}\text { Decimal } \\
\text { positive values, } \\
\text { in } \mathrm{mm}\end{array}$ & The stud spacing, decided by the designer. \\
\hline $\begin{array}{l}\text { Characteristic timber } \\
\text { density } \rho_{\mathrm{k}}\end{array}$ & $\begin{array}{l}\text { Decimal } \\
\text { positive values, } \\
\text { in } \mathrm{kg} / \mathrm{m}^{3}\end{array}$ & $\begin{array}{l}\text { The 5-percentile value of the density of the } \\
\text { material of the stud and battens (typically } \\
\text { softwood timber), before limit state factors have } \\
\text { been applied. } \\
\text { This is typically taken from EN } 338 \text { [106], or } \\
\text { values are provided by the manufacturer } \\
\text { following the processes described in EN } 339 \\
\text { [107]. }\end{array}$ \\
\hline Batten cross-section & $\begin{array}{l}\text { Decimal } \\
\text { positive values, } \\
\text { in } \mathrm{mm}\end{array}$ & $\begin{array}{l}\text { The width and depth of the batten cross-section, } \\
\text { in } \mathrm{mm} \text {, as decided by the designer. A typical } 50 \mathrm{x} \\
80 \mathrm{~mm} \text { batten is given as a default. }\end{array}$ \\
\hline \multicolumn{3}{|c|}{ Microscopic parameters } \\
\hline Fastener thread diameter $\mathrm{d}_{1}$ & $\begin{array}{l}\text { Decimal } \\
\text { positive values, } \\
\text { in } \mathrm{mm}\end{array}$ & $\begin{array}{l}\text { The thread diameter of the screw, decided by the } \\
\text { designer. }\end{array}$ \\
\hline Fastener head diameter $d_{h}$ & $\begin{array}{l}\text { Decimal } \\
\text { positive values, } \\
\text { in } \mathrm{mm}\end{array}$ & $\begin{array}{l}\text { The head diameter of the screw, derived from the } \\
\text { thread diameter the designer has selected, based } \\
\text { on the options on a manufacturer's catalogue. }\end{array}$ \\
\hline Stud penetration length $t_{\text {pen }}$ & $\begin{array}{l}\text { Decimal } \\
\text { positive values, } \\
\text { in } \mathrm{mm}\end{array}$ & $\begin{array}{l}\text { This is derived from the fastener length the } \\
\text { designer intends to use. }\end{array}$ \\
\hline $\begin{array}{l}\text { Characteristic axial } \\
\text { withdrawal strength } \mathrm{f}_{\mathrm{ax}, \mathrm{k}}\end{array}$ & $\begin{array}{l}\text { Decimal } \\
\text { positive values, } \\
\text { in } \mathrm{MPa}\end{array}$ & $\begin{array}{l}\text { The characteristic withdrawal parameter } \\
\text { perpendicular to the grain, provided by the } \\
\text { fastener manufacturer and determined according } \\
\text { to EN14592 [90]. }\end{array}$ \\
\hline $\begin{array}{l}\text { Characteristic pull-through } \\
\text { strength } \mathrm{f}_{\mathrm{ax}, \mathrm{k}}\end{array}$ & $\begin{array}{l}\text { Decimal } \\
\text { positive values, } \\
\text { in } \mathrm{MPa}\end{array}$ & $\begin{array}{l}\text { The characteristic pull-through parameter of the } \\
\text { screw, provided by the fastener manufacturer and } \\
\text { determined according to EN14592 [90]. }\end{array}$ \\
\hline Associated density $\rho_{\mathrm{hss}}$ & $\begin{array}{l}\text { Decimal } \\
\text { positive values, } \\
\text { in } \mathrm{kg} / \mathrm{m}^{3}\end{array}$ & $\begin{array}{l}\text { The associated timber density used to calculate } \\
\text { the withdrawal parameter perpendicular to the } \\
\text { grain. This is provided by the fastener } \\
\text { manufacturer and determined according to } \\
\text { EN14592 [90]. }\end{array}$ \\
\hline Associated density $\rho_{\mathrm{pss}}$ & $\begin{array}{l}\text { Decimal } \\
\text { positive values, } \\
\text { in } \mathrm{kg} / \mathrm{m}^{3}\end{array}$ & $\begin{array}{l}\text { The associated timber density used to calculate } \\
\text { the characteristic pull-through parameter of the } \\
\text { screw, provided by the fastener manufacturer and } \\
\text { determined according to EN14592 [90]. }\end{array}$ \\
\hline
\end{tabular}

In order to calculate the total withdrawal capacity of the selected fastener, the object needs to calculate a number of intermediate parameters. These are summarized in Table 6.

Table 6. Categorisation of automatically calculated Instance parameters 


\begin{tabular}{|l|l|l|}
\hline \multicolumn{2}{|c|}{ Macroscopic parameters } \\
\hline Panel length $\mathrm{L}$ & $\begin{array}{l}\text { Decimal } \\
\text { positive values, } \\
\text { in mm }\end{array}$ & $\begin{array}{l}\text { The total length of the panel, derived from the } \\
\text { stud centres the designer has selected. }\end{array}$ \\
\hline Panel volume V & $\begin{array}{l}\text { Decimal } \\
\text { positive values, } \\
\text { in } \mathrm{m}^{3}\end{array}$ & $\begin{array}{l}\text { The volume of the panels, derived from the panel } \\
\text { length, height, and thickness. }\end{array}$ \\
\hline \multicolumn{3}{|c|}{ Microscopic parameters } \\
\hline Total fastener length $\mathrm{l}_{\mathrm{f}}$ & $\begin{array}{l}\text { Decimal } \\
\text { positive values, } \\
\text { in mm }\end{array}$ & $\begin{array}{l}\text { The minimum allowable fastener length to } \\
\text { achieve the desired performance, derived from } \\
\text { the penetration length and the batten thickness. }\end{array}$ \\
\hline $\begin{array}{l}\text { Effective thread diameter } \\
\mathrm{d}_{\mathrm{ef}}\end{array}$ & $\begin{array}{l}\text { Decimal } \\
\text { positive values, } \\
\text { in mm }\end{array}$ & $\begin{array}{l}\text { The effective thread diameter for calculation } \\
\text { purposes, according to the guidance given in } \\
\text { Eurocode 5 [83]. }\end{array}$ \\
\hline Diameter factor $\mathrm{k}_{\mathrm{h}}$ & $\begin{array}{l}\text { Decimal } \\
\text { positive values, } \\
\text { unitless }\end{array}$ & $\begin{array}{l}\text { The ratio between the head and the thread } \\
\text { diameter. This is introduced as an intermediate } \\
\text { variable for calculation purposes. More } \\
\text { information can be found in previous work by the } \\
\text { authors [105]. }\end{array}$ \\
\hline
\end{tabular}

The final output is the characteristic axial capacity $\mathrm{F}_{\mathrm{ax}, \mathrm{Rk}}$ is provided automatically. All intermediate calculations are presented to the user in non-editable mode, to allow for manual verification, if desired.

The calculation process itself required the introduction of a number of intermediate terms for model validation, as well as ease of calculation. In addition, approximate values had to be provided for standard mathematical constants (Figure 15). 


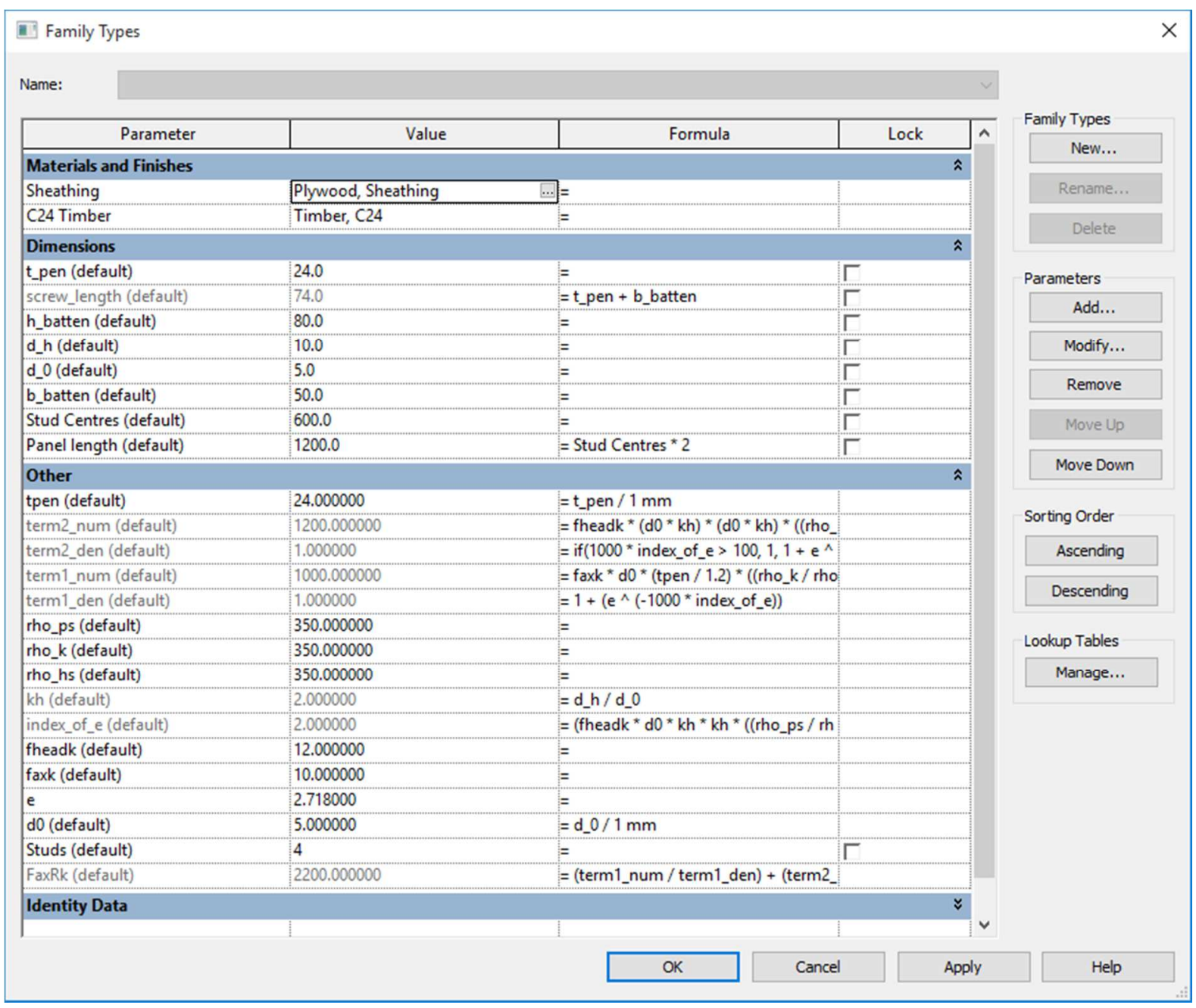

Figure 15. Properties of the family type.

\section{Prospects, Challenges, and Implications for ACC in BIM}

\subsection{Generalisation of a BIM Framework in ACC}

The strongest aspect of the process described in Sections 3 and 4 is the fact that it can be easily generalised for any type of computation-based code checking. It is particularly applicable in the case of structural engineering as this is typically the most computationally intensive aspect of building design; it can, however, be applied equally well in other engineering aspects such as geotechnical engineering, hydraulic engineering, and building services. In addition, it is fully compatible with existing ACC approaches in the literature.

The introduction of MDDF as a way of isolating recursive engineering problems to single equations allows the development of appropriate knowledge domains. As MDDF is domain agnostic, it also allows extension for solution of multi-disciplinary problems. For example, MDDF analysis of a design component could take into account architectural technology properties (materials, finishes, thermal and sound insulation properties), structural properties (geometry, materials), and quantity surveying properties (costing/pricing). These could be categorised based on geographical location, thus allowing the development of different knowledge bases per locale. The geographic location could influence aspects such as the local Building Regulations (including both insulation and applicable structural design code of practice) and available vendors (affecting costing and pricing). Individual 
ACC equations could be built for each of these categories, and then combined in one "master" ACC model per component, using MDDF processes of the type described in the case studies above. This would then enable the development of a highly optimized database of Smart BIM components, as per Section 4. A schematic representation of this approach is given in Figure 16.

The utilisation of such components would not only ensure code compliance but would also provide the designer with instant feedback of the implications of the various design options, thus supporting true evidence-based design. Theoretically, a design that would rest entirely on such ACC components would not require engineering input. Obviously, the realisation of such a vision in its entirety is still a long way ahead, as will be further detailed in the next section of this work. However, the fact that the process described here makes it feasible in principle highlights the potential of the approach.

[text continues after landscape-oriented diagram] 


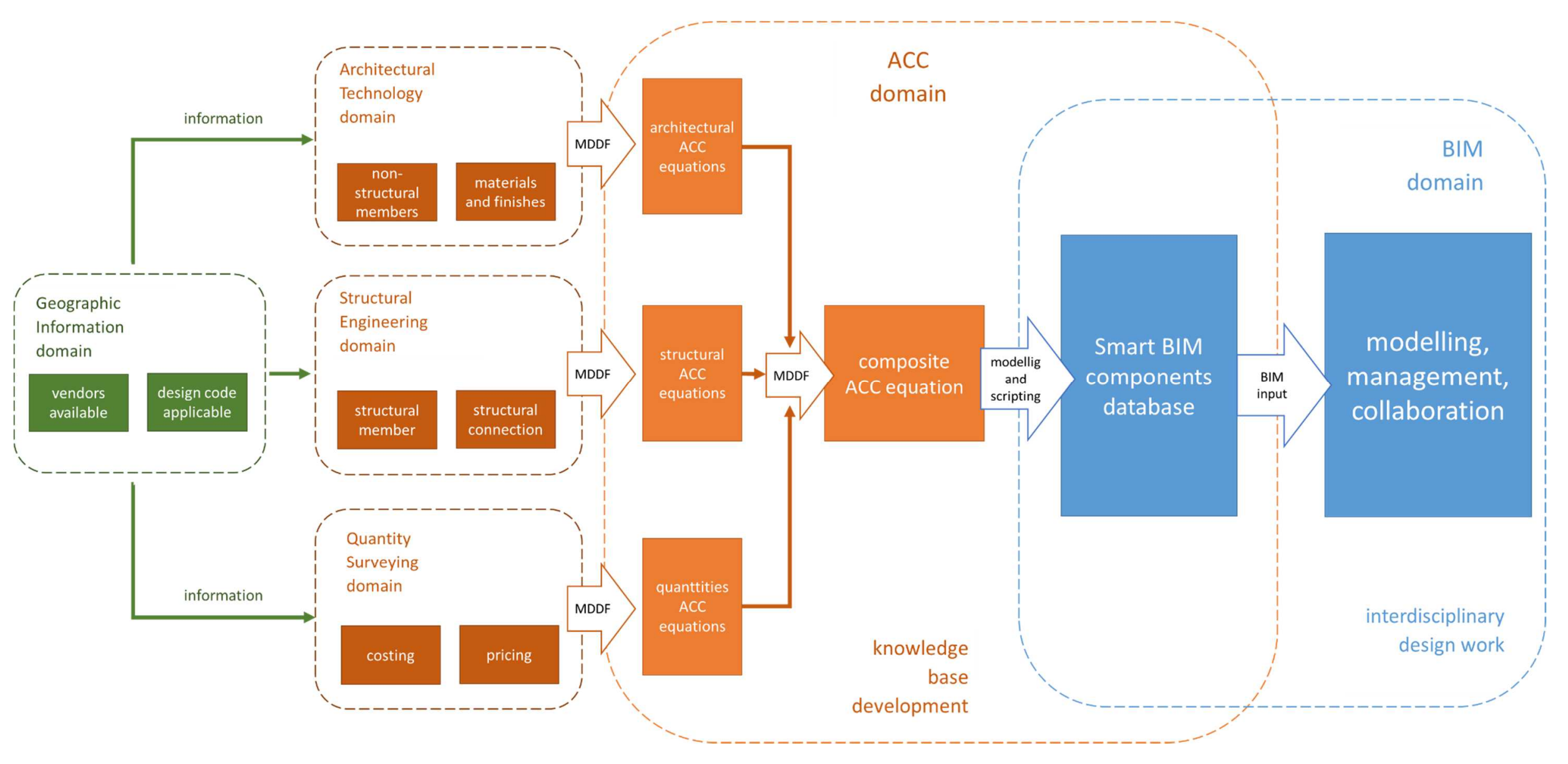

Fig. 16. Schematic representation of the development of a multi-disciplinary automated BIM process 


\subsection{Limitations}

Naturally, the work presented in this paper does not deal with ACC conclusively, nor does it present a ready-to-market commercial-level system. Instead, it is intended to act as a proof-of-concept, demonstrating the feasibility of delivering effective ACC within an SP-BIM system with the current state-of-the-art in software and hardware, as well as highlighting the potential of the ACC concept more generally and the implications it has for changing building design as we currently understand it.

The limitations of the work can be separated in two categories: those with regard to the extension of a greater, multi-disciplinary scale as discussed in the previous section, and those with regard to the philosophy of the concept itself.

\subsubsection{Extending ACC to more complex problems}

Like many similar methods, the computational load of the MDDF approach increases exponentially to the complexity of the problem at hand. The case studies developed for the purposes of this work focused on the key controlling aspect of the design of such fasteners (the ductile failure of the connection). A complete connection, solved according to Eurocode 5, would require taking into account additional aspects such as fastener distances, the possibility of splitting, cumulative effects such as plug and block shear, etc., thus further increasing the computational load. Particularly complex problems, such as moment-resisting connections, that already require a significant computational load with existing methods of analysis [108], might create significant challenges. Dealing with multi-disciplinary problems would increase this load further.

It is important to note, however, that this increase in complexity affects only the MDDF and not the BIM side. Indeed, a core advantage of this method is that it condenses highly complex calculations in a single equation thus minimizing the computational workload for the BIM software. As such, only the building of the knowledge base is computationally expensive; the Smart BIM components in design practice have practically the same performance as standard ("not smart") BIM components. Similarly, the implementation of the knowledge base is time-consuming. However, the development of the Smart BIM component database needs to happen only once. While a fully-fledged Smart BIM database covering all aspects of a building design code is outside the capacity of a single developer, or even a small practice, it is certainly feasible for a mid-size software vendor.

Some limitations remain: the work presented in this paper focused on single components, without system interaction at building level. Thus, certain aspects remain outside its scope: for example, the state-of-the-art in computational structural analysis cannot be implemented with an MDDF process. This, however, is an almost tautological limitation: by definition the state-of-the-art in computational structural analysis, pushes to the limit the capacity of existing software and hardware, thus not allowing additional computational overhead for any other process or optimization. Naturally, one-off, monumental projects that push the artistic and scientific state-of-the-art will always require bespoke solutions. Those projects, however, are already outside the purview of design codes and thus outside the scope of ACC.

\subsubsection{Consequences of the ACC approach}

Adopting ACC for building design has two fundamental consequences. Firstly, the MDDF approach conceals the physical behaviour of the structural system. This is in contrast to contemporary structural engineering practice, where the design code equations roughly reflect the findings of research and provide some insight of the failure mechanisms, thus allowing the engineer to make informed decisions on structural performance. An approach such as the one presented in this paper removes this advantage. Instead, the ACC components function as "black boxes": the designer might be certain that they fulfil the requirements of the code, but s/he is not able to interpret the process via which these requirements are met. In a situation where these are developed by a commercial software vendor, as 
would be the most likely scenario, the supporting calculations might be hidden from the user altogether.

A second issue involves the inherent limits ACC poses on architectural expression, formal freedom, and construction creativity. A downside to ACC is that only solutions that have been fully analysed, and their solutions computed and integrated, can be used by the designer. As the addition of an ACC component has overheads for the development party, it is likely that the range of ACC components will be smaller than those for BIM. A summary of the respective advantages, overheads, and limitations of pre-made components in Computer-Aided Design (CAD), BIM, and ACC BIM is given in Table 7. The assessment of the technologies is based on the in-built features of the main software packages; it does not take into account add-ons and plug-ins that individual users with computer programming capacity might develop independently as this is an extension of the core technology.

Table 7. Comparison of CAD, BIM, and ACC BIM with regard to development overhead, design flexibility, and intelligent behaviour

\begin{tabular}{|c|c|c|c|}
\hline Technology & Development Overheads & Design Flexibility & Intelligent Behaviour \\
\hline CAD & $\begin{array}{l}\text { None required for standard } \\
\text { use. } \\
\text { Instanced geometry, in the } \\
\text { form of Blocks or Templates } \\
\text { is widely available and can be } \\
\text { developed by the user with } \\
\text { little additional effort. }\end{array}$ & $\begin{array}{l}\text { Very high design } \\
\text { flexibility; the user is } \\
\text { limited only by the } \\
\text { geometry s/he can } \\
\text { draw on screen. }\end{array}$ & $\begin{array}{l}\text { Instanced geometry } \\
\text { can save time, allow } \\
\text { for consistency across } \\
\text { drawings, reduce file } \\
\text { sizes [109]. However, } \\
\text { typically instanced } \\
\text { geometry does not } \\
\text { provide anything } \\
\text { beyond the geometry } \\
\text { itself. }\end{array}$ \\
\hline BIM & $\begin{array}{l}\text { BIM software requires the } \\
\text { software developer to provide } \\
\text { a wide range of components } \\
\text { with pre-programmed } \\
\text { behaviour (e.g. System } \\
\text { Families in Autodesk Revit). } \\
\text { Additional components can be } \\
\text { developed by third parties, } \\
\text { however, there are overheads } \\
\text { partly with regard to } \\
\text { modelling but mostly with the } \\
\text { required scripting and } \\
\text { parametrization. }\end{array}$ & $\begin{array}{l}\text { High design } \\
\text { flexibility; } \\
\text { components need to } \\
\text { adhere to the } \\
\text { constraints set by their } \\
\text { Family type, which } \\
\text { are typically } \\
\text { geometry-based. }\end{array}$ & $\begin{array}{l}\text { The component-based } \\
\text { nature of BIM means } \\
\text { that there are gains in } \\
\text { productivity, clash } \\
\text { detection, and project } \\
\text { costing [110]. } \\
\text { However, most } \\
\text { intelligent behaviour } \\
\text { is restricted to either } \\
\text { geometry interaction } \\
\text { (e.g. a door hosted in a } \\
\text { wall) or technical } \\
\text { information with basic } \\
\text { calculations (e.g. U- } \\
\text { value of a wall). }\end{array}$ \\
\hline ACC BIM & $\begin{array}{l}\text { ACC BIM requires the } \\
\text { analysis of the components, } \\
\text { the development of the ACC } \\
\text { behaviour, and the } \\
\text { implementation in an existing } \\
\text { BIM component. } \\
\text { The process needs to be } \\
\text { repeated for every new ACC- } \\
\text { enabled component. }\end{array}$ & $\begin{array}{l}\text { Medium-to-low } \\
\text { design flexibility; } \\
\text { depending on the type } \\
\text { of component and } \\
\text { how it has been } \\
\text { implemented, the user } \\
\text { is restricted to the } \\
\text { available choices. }\end{array}$ & $\begin{array}{l}\text { By definition, ACC- } \\
\text { produced models are } \\
\text { code compliant. }\end{array}$ \\
\hline
\end{tabular}


Naturally, a designer could choose to use a mixture of non-ACC and ACC components, much like a designer can now choose to use basic CAD-level geometry in a BIM package, without making use of default BIM behaviour. This, however, would mean that the input of an expert would still be required, partially negating the concept of ACC. As such, ACC is unlikely to be suitable for projects where high design flexibility is required, non-standard construction technologies are applied, or other atypical conditions are encountered.

\subsection{Applicability and Implications}

Despite these limitations, ACC does have significant potential for AEC, as it fits with a range of existing initiatives, agendas, and paradigms. Firstly, the majority of building design does follow repetitive patterns and standardized processes, and it is likely that it'll continue to do so in the future. Indeed, the standardisation of construction, and its adoption of concepts, models, and methods from other industries, such as manufacturing, has been a recurring theme, from Le Corbusier [111] to the UK Egan report [112].

ACC is particularly well placed to serve the concept of Modern Methods of Construction (MMC). MMCs emphasize the use of off-site manufactured elements, from individual components to full volumetric assemblies [113, 114]. As such, MMC-based designs rely on a componentized, as opposed to an ad hoc, approach. Moreover, such components and assemblies already have development overheads and production costs and are produced by manufacturers above a certain size threshold. Such providers are both more likely to be able to take on the additional overheads posed by ACC, and see the advantages offered by economies of scale.

The utilization of ACC by designers, manufacturers, and adopters of mass-produced elements would allow one more potential benefit of MDDF-based ACC to be realised. The MDDF environment needs to be set only once: additional data can simply be fed into the system, and the resulting equations will be amended automatically. While the proof-of-concept examples presented here do not include a capacity for automatic updating of the BIM components as well, this is feasible in principle, and it could be developed by a software vendor that decided to implement ACC-enabled BIM at a large scale. This effectively means that the MDDF-equations, and thus the ACC elements, could be optimised as more real-world data points are collected, without development overheads. The increased emphasis on post-occupancy evaluation [115], structural health monitoring [116], and lifecycle management [117] means both that more data will be collected from buildings, and increased attention will be paid to optimization. Approaches such as those presented in this work can make use of and support these developments.

\section{Conclusions}

This paper presented a novel BIM-based system for the automatic code compliance of structural timber design. Two case studies were given as proof-of-concept. The first relied on pre-calculated capacities and spacings by the manufacturer of timber joists. The second utilised the mathematical method of MDDF in order to develop BIM components that enable the designer to have codecompliant design outputs automatically, without needing to perform detailed structural design processes. 'Smart' BIM components that are automatically code-compliant were implemented in a popular BIM-based software package, demonstrating the capacity to apply the method with the current software and hardware state-of-the-art. The authors are currently working on expanding the approach presented here to other, more complex, types of connection, while a main research aim for the future is to increase the scale from multi-variable single-component to whole-building multi- 
component, which involves a different level of conceptual and computational complexity, and introduces a range of new challenges.

The research does not claim to have solved all issues with ACC. As other researchers have pointed out, a fully automated code-checking system is many years away [38, 44]; a system or software package that allows a designer to produce automatically code-compliant designs, by providing instant feedback on code compliance and/or adjusting elements automatically or semiautomatically so as to be code-compliant is likely to take even longer. Additional complexity is introduced by the fact that design codes change and expand continuously, both in number, by codifying new areas and aspects of building design, and in-depth, by increasing the complexity and level of detail of existing areas. Moreover, the state-of-the-art in architectural and engineering design is unlikely to rely on codified design; instead, it is likely to use the equivalent state-of-the-art in hardware, software, and physical testing to push forward what is possible.

However, none of the above challenges take away from the potential of ACC. The proliferation of design codes means that any aspect of automation of those becomes more useful. The continuously increasing hardware power and improvements in commercial software mean that more can be delivered by large-scale vendors. The increasing prevalence of BIM at all levels of practice, the introduction of professional software engineers in cutting-edge AEC companies, and the continuous simplification of the Application Programming Interfaces (API) of established software packages via more accessible high-level programming languages mean that software customisation is more accessible than ever and is highly likely to continue to be so. Finally, the push towards more offsite manufacturing means that the componentisation of design will continue to expand; ACC is particularly well-placed to contribute to that agenda.

In the short term, ACC is more likely to be implemented partially and progressively. Manufacturers of offsite components and assemblies are the ones that are most likely to develop ACC tools and BIM components in order to make the adoption of their products by designers more attractive. Designs with a combination of ACC components and assemblies designed ad hoc will be more prevalent. Hopefully, the work presented in this paper can contribute to this process. 


\section{References}

1. BuildingSMART. Technical Vision. 2016 [cited 20162 December]; Available from: http://buildingsmart.org/standards/technical-vision/.

2. Russell, P. and D. Elger. The Meaning of BIM. in Architecture in Computro -26th eCAADe Conference Proceedings. 2008. Antwerpen.

3. Björk, B.-C., Basic structure of a proposed building product model. Computer Aided Design, 1989. 21(2): p. 71-78.

4. Ding, L., Y. Zhou, and B. Akinci, Building Information Modeling (BIM) application framework: The process of expanding from $3 D$ to computable $n D$. Automation in Construction, 2014. 46: p. 82-93.

5. Eastman, C., et al., BIM handbook: A guide to building information modeling for owners, managers, designers, engineers and contractors. 2011: John Wiley and sons.

6. Arayici, Y., et al., Technology adoption in the BIM implementation for lean architectural practice. Automation in Construction, 2011. 20(2): p. 189-195.

7. Penttilä, H., Early architectural design and BIM, in Computer-Aided Architectural Design Futures. 2007, Springer: Netherlands. p. 291-302.

8. $\quad$ Cheung, F.K., et al., Early stage multi-level cost estimation for schematic BIM models. Automation in Construction, 2012. 27: p. 67-77.

9. Smith, P., BIM \& the 5D project cost manager. Procedia-Social and Behavioral Sciences, 2014. 119: p. 475-484.

10. Abanda, F.H. and L. Byers, An investigation of the impact of building orientation on energy consumption in a domestic building using emerging BIM (Building Information Modelling). Energy, 2016. 97: p. 517-527.

11. Poirier, E.A., S. Staub-French, and D. Forgues, Measuring the impact of BIM on labor productivity in a small specialty contracting enterprise through action-research. Automation in Construction, 2015. 58: p. 74-84.

12. Autodesk. Robot Structural Analysis Software. 2016; Available from: http://www.autodesk.co.uk/products/robot-structural-analysis/overview.

13. TEKLA. Structural Designer. 2016; Available from: https://www.tekla.com/uk/products/tekla-structural-designer.

14. Computers \& Structures Inc. Building Information Modeling. 2016; Available from: https://www.csiamerica.com/building-information-modeling.

15. Schinler, D. and E. Nelson, BIM and the Structural Engineering Community, in STRUCTURE. 2008. p. 10-12.

16. Volk, R., J. Stengel, and F. Schultmann, Building Information Modeling (BIM) for existing buildings - Literature review and future needs. Automation in Construction, 2014. 38: p. 109-127.

17. Marasini, R. and P. Patlakas. Is there a business case for small to medium enterprises (SMES) to use building information modelling? in 1st UK Academic conference on BIM. 2012. Newcastle, UK.

18. Boland Jr, R.J., K. Lyytinen, and Y. Yoo, Wakes of innovation in project networks: The case of digital 3-D representations in architecture, engineering, and construction. Organization science, 2007. 18(4): p. 631-647.

19. Shen, W., et al., Systems integration and collaboration in architecture, engineering, construction, and facilities management: A review. Advanced engineering informatics, 2010. 24(2): p. 196-207.

20. IStructE and TRADA, Manual for the design of timber building structures to Eurocode 5. 2007, London: The Institution of Structural Engineers.

21. Computers and Structures Inc. SAP2000 - Compare Levels. 2016 [cited 201615 December]; Available from: https://www.csiamerica.com/products/sap2000/compare-levels.

22. Autodesk. Robot Structural Analysis - Timber Design. 201415 Dec 2016]; Available from: https://knowledge.autodesk.com/support/robot-structural-analysis-products/learnexplore/caas/CloudHelp/cloudhelp/2014/ENU/Robot/files/GUID-6E2262BF-610E-421AA342-33D7BE012925-htm.html. 
23. Ltd, T.R.E. Teretron. 2016 [cited 201615 December]; Available from:

https://www.teretron.com/.

24. Succar, B., Building information modelling framework: A research and delivery foundation for industry stakeholders. Automation in Construction, 2009. 18(3): p. 357-375.

25. NBS. BIM Levels explained. 201415 December 2016]; Available from: https://www.thenbs.com/knowledge/bim-levels-explained.

26. Wang, Y., et al., Engagement of Facilities Management in Design Stage through BIM: Framework and a Case Study. Advances in Civil Engineering, 2013. 2013: p. 8.

27. McArthur, J.J., A Building Information Management (BIM) Framework and Supporting Case Study for Existing Building Operations, Maintenance and Sustainability. Procedia Engineering, 2015. 118: p. 1104-1111.

28. Song, S., J. Yang, and N. Kim, Development of a BIM-based structural framework optimization and simulation system for building construction. Computers in Industry, 2012. 63(9): p. 895-912.

29. Porwal, A. and K.N. Hewage, Building Information Modeling (BIM) partnering framework for public construction projects. Automation in Construction, 2013. 31: p. 204-214.

30. Choi, B., et al., Framework for Work-Space Planning Using Four-Dimensional BIM in Construction Projects. Journal of Construction Engineering and Management, 2014.

31. Chavada, R., N. Dawood, and M. Kassem, Construction workspace management: the development and application of a novel $n D$ planning approach and tool. Journal of Information Technology in Construction (ITcon), 2012. 17: p. 213-236.

32. Kim, M.-K., et al., A framework for dimensional and surface quality assessment of precast concrete elements using BIM and 3 D laser scanning. Automation in Construction, 2015. 49, Part B: p. 225-238.

33. Park, C.-S., et al., A framework for proactive construction defect management using BIM, augmented reality and ontology-based data collection template. Automation in Construction, 2013. 33: p. 61-71.

34. Cerovsek, T., A review and outlook for a 'Building Information Model' (BIM): A multistandpoint framework for technological development. Advanced Engineering Informatics, 2011. 25(2): p. 224-244.

35. Singh, V., N. Gu, and X. Wang, A theoretical framework of a BIM-based multi-disciplinary collaboration platform. Automation in Construction, 2011. 20(2): p. 134-144.

36. Lu, W. and T. Olofsson, Building information modeling and discrete event simulation: Towards an integrated framework. Automation in Construction, 2014. 44: p. 73-83.

37. Kadolsky, M., K. Baumgärtel, and R.J. Scherer, An Ontology Framework for Rule-based Inspection of eeBIM-systems. Procedia Engineering, 2014. 85: p. 293-301.

38. Hofmeyer, H. and M. Bakker, Spatial to kinematically determined structural transformations. Advanced Engineering Informatics, 2008. 22(3): p. 393-409.

39. Lee, S.-I., J.-S. Bae, and Y.S. Cho, Efficiency analysis of Set-based Design with structural building information modeling (S-BIM) on high-rise building structures. Automation in Construction, 2012. 23: p. 20-32.

40. Fenves, S.J., Tabular decision logic for structural design. Journal of the Structural Division, 1966. 92(6): p. 473-490.

41. Fenves, S.J., E.H. Gaylord, and S.K. Goel, Decision table formulation of the 1969 AISC specification. 1969, University of Illinois Engineering Experiment Station. College of Engineering. University of Illinois at Urbana-Champaign.

42. Xiangyang, T., F. Paul, and H. Amin, Automated Code Compliance Checking for Building Envelope Design. 2010.

43. Tan, X., A. Hammad, and P. Fazio, Automated code compliance checking for building envelope design. Journal of Computing in Civil Engineering, 2010.

44. Eastman, C., et al., Automatic rule-based checking of building designs. Automation in Construction, 2009. 18(8): p. 1011-1033.

45. Lee, J.M., Automated checking of building requirements on circulation over a range of design phases. 2010, Georgia Institute of Technology. 
46. Zhang, J. and N.M. El-Gohary, Automated Information Transformation for Automated Regulatory Compliance Checking in Construction. Journal of Computing in Civil Engineering, 2015: p. B4015001.

47. Lee, H., et al., Translating building legislation into a computer-executable format for evaluating building permit requirements. Automation in Construction, 2016. 71: p. 49-61.

48. Solihin, W., A simplified BIM data representation using a relational database schema for an efficient rule checking system and its associated rule checking language. 2015, Georgia Institute of Technology.

49. Salama, D. and N. El-Gohary, Semantic modeling for automated compliance checking, in Computing in Civil Engineering (2011). 2011. p. 641-648.

50. Yurchyshyna, A., et al. Towards an ontology-based approach for formalisation of expert knowledge in conformity checking model in construction. in Technology Management Conference (ICE), 2008 IEEE International. 2008. IEEE.

51. Zhong, B., et al., Ontology-based semantic modeling of regulation constraint for automated construction quality compliance checking. Automation in Construction, 2012. 28: p. 58-70.

52. Yang, Q. and X. Li, Representation and execution of building codes for automated code checking, in Computer Aided Architectural Design Futures 2001. 2001, Springer. p. 315-329.

53. Khemlani, L., CORENET e-PlanCheck: Singapore's automated code checking system. AECbytes, October, 2005.

54. Drogemuller, R., et al., Automated code checking. 2004.

55. Ding, L., et al., Automating code checking for building designs-DesignCheck. 2006.

56. Dimyadi, J. and R. Amor, Automated Building Code Compliance Checking-Where is it at. Proceedings of CIB WBC, 2013: p. 172-185.

57. Balaban, Ö., E.S.Y. Kilimci, and G. Cagdas, Automated Code Compliance Checking Model for Fire Egress Codes. 2012.

58. Malsane, S., et al., Development of an object model for automated compliance checking. Automation in Construction, 2015. 49: p. 51-58.

59. Ha, T.H.N.-K.H. and C. Bedard. Architectural and structural design with code compliance checking. in 3rd Design and Decision Support Systems in Architecture and Urban Planning. 1996. Belgium.

60. Solihin, W. and C. Eastman, Classification of rules for automated BIM rule checking development. Automation in Construction, 2015. 53: p. 69-82.

61. Michalski, R.S., J.G. Carbonell, and T.M. Mitchell, Machine learning: An artificial intelligence approach. 2013: Springer Science \& Business Media.

62. Steiner, B., et al. Integrated Structural-Architectural Design for Interactive Planning. in Computer Graphics Forum. 2017. Wiley Online Library.

63. Scherer, R. and A. Gehre, An approach to a knowledge-based design assistant system for conceptual structural system design. Proc., ECPPM 2000, Product and Process Modeling in Building and Construction, 2000: p. 229-238.

64. Sacks, R., A. Warszawski, and U. Kirsch, Structural design in an automated building system. Automation in Construction, 2000. 10(1): p. 181-197.

65. Mora, R., H. Rivard, and C. Bédard, Computer representation to support conceptual structural design within a building architectural context. Journal of Computing in Civil Engineering, 2006. 20(2): p. 76-87.

66. Mora, R., C. Bédard, and H. Rivard, A geometric modelling framework for conceptual structural design from early digital architectural models. Advanced Engineering Informatics, 2008. 22(2): p. 254-270.

67. Luth, G.P., et al., A formal approach to automating conceptual structural design, Part I: Methology. Engineering with Computers, 1991. 7(2): p. 79-89.

68. Huang, L., M. Breit, and M. Mensinger. Approach to handle architectural flexibility requirements for automated structural design proposals of steel concrete office buildings in early design phases. in Proc. 2012 EG-ICE Workshop, Herrsching, Germany, July. 2012.

69. Hofmeyer, H., Cyclic application of transformations using scales for spatially or structurally determined design. Automation in construction, 2007. 16(5): p. 664-673. 
70. Fenves, S.J., H. Rivard, and N. Gomez, SEED-Config: a tool for conceptual structural design in a collaborative building design environment. Artificial Intelligence in Engineering, 2000. 14(3): p. 233-247.

71. Breit, M., et al. Serious Play: Intuitive Architectural Conceptual De-Sign With Immediate Structural Feedback and Eco-Nomical and Ecological Performance Predictions. in Proc. 12th International Conference on Construction Applications of Virtual Reality. 2012.

72. Rafiq, M., et al., Visualizing search and solution spaces in the optimum design of biaxial columns. Journal of computing in civil engineering, 2006. 20(2): p. 88-98.

73. James, M. and J.J. Odell, Object-Oriented Methods: A Foundation. 1995, Prentice Hall.

74. Ismail, A., K. Ali, and N. Iahad, A Review on BIM-based automated code compliance checking system, in 5th International Conference on Research and Innovation in Information Systems (ICRIIS). 2017: Langkawi, Malaysia. p. 1-6.

75. Sacks, R., Issues in the development and implementation of a building project model for an automated building system. International Journal of Construction Information Technology, 1997. 5: p. 75-101.

76. Sacks, R., Integrated AEC information services using object methods and a central project model. Computer-Aided Civil and Infrastructure Engineering, 2002. 17(6): p. 449-456.

77. Belsky, M., R. Sacks, and I. Brilakis, Semantic enrichment for building information modeling. Computer-Aided Civil and Infrastructure Engineering, 2016. 31(4): p. 261-274.

78. Clarke, M. and P. Harley, How smart is your content? Using semantic enrichment to improve your user experience and your bottom line. Science Editor, 2014. 37(2): p. 40-44.

79. Fionna, C., Structural Engineer's Pocket Book: Eurocodes. 2014: CRC Press.

80. KLH, Structural Pre-Analysis Tables. 2012: Katsch, Murau.

81. Mitek. PAMIR Software. 15/2/2017]; Available from: http://www.mitek.co.uk/PAMIR/.

82. Wiehag. Solid Timber Solutions. 15/2/2017]; Available from: http://timberconstruction.wiehag.com/uploads/tx lbrdownloadssimple/WIEHAG_Company brochure English 01.pdf.

83. CEN, BS EN 1995-1-1:2004+A2:2014, Eurocode 5: Design of timber structures. General. Common rules and rules for buildings. 2014, BSI.

84. BSI, BS 5268-2:2002 Structural use of timber. Code of practice for permissible stress design, materials and workmanship. 2002, BSI: London.

85. Livingstone, A., et al. The Case for Mass Customisation of Structural Timber Design. in Structures Congress 2015. 2015. Portland, OR: ASCE.

86. Ltd, J.J.S., JJI-Joists Technical Manual. 4th ed. 2013, Forres: James Jones \& Sons Ltd.

87. Autodesk. Parametric components. 2017 21/02/2017]; Available from: http://www.autodesk.co.uk/products/revit-family/features/platform/parametric-components.

88. Beck, D. Solent BIM Library. 2015 21/02/2017]; Available from: http://solentbimlibrary.weebly.com/.

89. Beck, D., Design and Development of Standardised BIM Componentsfor the Offsite Timber Manufacturing Industry. 2015, Southampton Solent University: Southampton.

90. CEN, BS EN 14592:2008+A1:2012 Timber structures. Dowel type fasteners. Requirements. 2012, BSI: London.

91. CEN, EN 1383: 1999; Timber structures. Test methods. Pull-through resistance of timber fasteners. . 1999: London.

92. Slonim, D.K., From patterns to pathways: gene expression data analysis comes of age. Nat Genet.

93. Abolfazl, M., A.A. Joshua, and W. Kermit, Population Synthesis with Subregion-Level Control Variable Aggregation. 2009.

94. Fang, L. and D.C. Gossard, Multidimensional curve fitting to unorganized data points by nonlinear minimization. Computer-Aided Design, 1995. 27(1): p. 48-58.

95. Garcke, J. and M. Hegland, Fitting multidimensional data using gradient penalties and the sparse grid combination technique. Computing, 2009. 84(1): p. 1-25.

96. Roger, S., Multidimensional scaling, tree-fitting, and clustering. . Science, 1980. 210(4468): p. 390-398. 
97. MathWorks. lsqcurvefit Documentation. Apr 3, 2017]; Available from: https://uk.mathworks.com/help/optim/ug/lsqcurvefit.html?s tid=gn loc drop.

98. Coleman, T. and Y. Li, On the Convergence of Reflective Newton Methods for Large-scale Nonlinear Minimization Subject to Bounds vol. 67. Ithaca, NY, USA: Cornell University, 1994.

99. Coleman, T.F. and Y. Li, An Interior Trust Region Approach for Nonlinear Minimization Subject to Bounds. SIAM Journal on Optimization, 1996. 6(2): p. 418-445.

100. Sorensen, D.C., Newton's Method with a Model Trust Region Modification. SIAM Journal on Numerical Analysis, 1982. 19(2): p. 409-426.

101. Levenberg, K., A method for the solution of certain non-linear problems in least squares. Quarterly of applied mathematics, 1944. 2(2): p. 164-168.

102. Marquardt, D.W., An algorithm for least-squares estimation of nonlinear parameters. Journal of the society for Industrial and Applied Mathematics, 1963. 11(2): p. 431-441.

103. Moré, J.J., The Levenberg-Marquardt algorithm: implementation and theory, in Numerical analysis. 1978, Springer. p. 105-116.

104. Bentler, P.M. and D.G. Bonett, Significance tests and goodness of fit in the analysis of covariance structures. Psychological bulletin, 1980. 88(3): p. 588.

105. Livingstone, A., et al. Multi-dimensional data fitting for the structural design of a simple timber connection. in World Conference on Timber Engineering (WCTE 2016). 2016. Vienna, Austria: Vienna University of Technology.

106. CEN, BS EN 338:2016 Structural timber - Strength classes. 2016, BSI: London.

107. CEN, BS EN 384:2016 Structural timber. Determination of characteristic values of mechanical properties and density. 2016, BSI: London.

108. Patlakas, P. and A. Thomson. An algorithm for the shear check of dowelled connections with combined moment and lateral loading. in Proceedings of the 2014 World Conference on Timber Engineering. 2014. Qubec City, Canada: FPInnovations.

109. Autodesk. CAD Blocks. 2017 Mar 20, 2017]; Available from: http://www.autodesk.com/solutions/cad-blocks.

110. Barlish, K. and K. Sullivan, How to measure the benefits of BIM - A case study approach. Automation in Construction, 2012. 24: p. 149-159.

111. Ågren, R. and R.D. Wing, Five moments in the history of industrialized building. Construction Management and Economics, 2014. 32(1-2): p. 7-15.

112. Egan, J., The Egan report-rethinking construction, in Report of the construction industry task force to the Deputy Prime Minister. . 1998, Department of Trade and Industry: London.

113. Hairstans, R., Off-Site and Modern Methods of Timber Construction: A Sustainable Approach. 2010: TRADA Technology Limited.

114. Ross, K., P. Cartwright, and O. Novakovic, A guide to modern methods of construction. 2006: IHS BRE Press.

115. Menezes, A.C., et al., Predicted vs. actual energy performance of non-domestic buildings: Using post-occupancy evaluation data to reduce the performance gap. Applied Energy, 2012. 97: p. 355-364.

116. Farrar, C.R. and N.A.J. Lieven, Damage prognosis: the future of structural health monitoring. Philosophical Transactions of the Royal Society A: Mathematical,

Physical and Engineering Sciences, 2007. 365(1851): p. 623-632.

117. Frangopol, D.M., Life-cycle performance, management, and optimisation of structural systems under uncertainty: accomplishments and challenges. Structure and Infrastructure Engineering, 2011. 7(6): p. 389-413. 